\title{
Effects of gastrointestinal delivery of non-caloric tastants on energy intake: a systematic review and meta-analysis
}

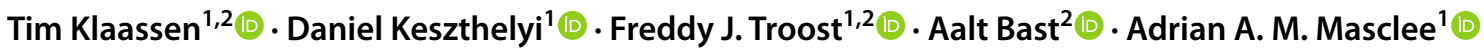

Received: 20 October 2020 / Accepted: 8 January 2021 / Published online: 8 February 2021

(c) The Author(s) 2021

\begin{abstract}
Purpose Taste receptors are expressed throughout the gastrointestinal tract. The activation of post-oral taste receptors using tastants could provide a non-invasive treatment option in combating the obesity epidemic. The aim of this review was to examine the effect of post-oral delivery of non-caloric tastants on eating behavior reflected by primary outcome energy intake and secondary outcomes GI symptoms and perceptions and potential underlying mechanisms. This review was conducted according to the PRISMA guidelines for systematic reviews.

Methods A systematic literature search of the Cochrane, PubMed, Embase, and Medline databases was performed. This systematic review and meta-analysis was registered in the PROSPERO database on 26 February 2020 (ID: CRD42020171182). Two researchers independently screened 11,912 articles and extracted information from 19 articles. If at least two studies investigated the effect of the same taste compound on primary outcome energy intake, a meta-analysis was performed to determine pooled effect sizes.

Results Nineteen papers including healthy volunteers were included. In the 19 papers analyzed, effects of various tastants were investigated in healthy volunteers. Most extensively investigated were bitter tastants. The meta-analysis of effects of bitter tastants showed a significant reduction in energy intake of $54.62 \mathrm{kcal}(95 \% \mathrm{CI}-78.54$ to $-30.69, p=0.0014)$.

Conclusions Bitter stimuli are most potent to influence eating behavior. Energy intake decreased after post-oral delivery of bitter tastants. This highlights the potential of a preventive role of bitter tastants in battling the obesity epidemic.
\end{abstract}

Keywords Taste $\cdot$ Energy intake $\cdot$ Eating behavior $\cdot$ Gastrointestinal $\cdot$ Satiety $\cdot$ Motility

\section{Introduction}

There are at least five prototypical basic tastes that can be distinguished by humans: sweet, sour, bitter, salty, and umami. More recent studies have pointed to the existence of other basic tastes (i.e., fat and starch) [1,2] as well as taste disorders such as metallic taste in cancer patients treated with chemotherapy [3]. Moreover, there is a phenomenon

Tim Klaassen

t.klaassen@maastrichtuniversity.nl

1 Division of Gastroenterology-Hepatology, Department of Internal Medicine, School of Nutrition and Translational Research in Metabolism (NUTRIM), Maastricht University Medical Center+, P.O. Box 5800, 6202 AZ Maastricht, The Netherlands

2 Food Innovation and Health, Center for Healthy Eating and Food Innovation, Maastricht University, 5911 AA Venlo, The Netherlands known as chemesthesis, which refers to chemical sensations that are perceived as warmth, heat, irritation, cooling, or pungency [4]. A prototypical pungent stimulus is capsaicin, resulting in a sizable number of studies investigating the effects of capsaicin as a weight loss intervention $[5,6]$.

As far as the prototypical basic tastes are concerned, these can be sensed by taste buds present on the tongue. Ion channels mediate the sensing of salty and sour taste, whereas sensing sweet, bitter and umami taste is mediated by two families of taste receptors. Taste receptor family 1 (TAS1) generally senses sweet and umami taste and taste receptor family 2 (TAS2) primarily senses bitter taste [7]. It is hypothesized that these prototypical tastes exist to predict the type of food that is ingested (i.e., sweet for saccharides, umami for glutamate, and bitter for potential toxic substances) [8]. However, it should be noted that several studies show that the negative affective response to bitter can be decoupled by, for instance, the positive response to caffeine $[9,10]$. In addition, several studies have shown 
that the activation of oral taste receptors can result in the release of gastrointestinal (GI) peptides such as peptide YY (PYY), glucagon-like peptide 1 (GLP-1), and cholecystokinin (CCK) [11, 12]. These GI peptides have been shown to influence eating behavior by reducing appetite sensations and food intake after intravenous administration [13-18].

Taste receptors are not only present on the tongue but are expressed throughout the entire human gut [19-22]. In the GI-tract, entero-endocrine cells (EECs) are co-localized with these taste receptors. The in vitro studies have shown that activation of these taste-receptors results in the release of GI peptides [23-25].

Activation of taste receptors can be elicited using noncaloric tastants. Taste receptor activation using non-caloric tastants to influence eating behavior is potentially considered as a non-invasive treatment option in combating the obesity epidemic [26]. This concept deserves further evaluation. To date, a significant number of papers [27-45] describing the effects of post-oral delivery of non-caloric tastants (i.e., exposure to tastants anywhere distal to the oral cavity) on eating behavior, and in particular energy intake, have been published. However, due to inconsistent results reported in these papers, the effect of post-oral delivery of non-caloric tastants on eating behavior remains unclear and a detailed overview of the literature on the effects of post-oral delivery of non-caloric tastants on eating behavior is lacking. Therefore, we conducted a systematic review and meta-analysis using the PRISMA guidelines for systematic reviews. In order to keep this review and meta-analysis concise, we focused on the prototypical basic tastes; novel taste entities and chemesthesis were deemed out of scope.

Our aim was to systematically address randomized controlled trials investigating the effects of post-oral delivery of prototypical non-caloric tastants versus placebo on energy intake in healthy volunteers. Our secondary aims were to evaluate the effects of post-oral delivery of non-caloric tastants versus placebo on GI symptoms and perceptions and potential underlying mechanisms in healthy volunteers. We hypothesized that post-oral delivery of non-caloric tastants results in decreased energy intake compared with placebo in healthy volunteers. Moreover, we hypothesized that post-oral delivery of non-caloric tastants results in increased satiation and the release of GI peptides as the primary mechanism of action. A meta-analysis was performed in case at least two studies described the use of non-caloric tastants of the same taste on the primary outcome energy intake and clinical heterogeneity was acceptable.

\section{Methods}

\section{Search strategy}

This systematic review and meta-analysis was registered in the PROSPERO database on 26 February 2020 (ID: CRD42020171182). The present systematic review and meta-analysis were performed according to the Preferred Reporting Items for Systematic Reviews and Meta-Analyses (PRISMA) guidelines [46]. The description of the PICOS (participants, intervention, comparison, outcome, and setting) criteria used to define the research question are depicted in Table 1. A structured search in the Cochrane, PubMed, Embase, and Medline databases was performed up to 26 February 2020 with the following search strategy: $(((()((()((\operatorname{tastant}))$ OR Taste) OR Taste receptor) OR bitter taste) OR quinine) OR denatonium benzoate) OR umami) OR sodium glutamate) OR monosodium glutamate) OR sweet) OR non-nutritive sweeteners)) AND ((()((()(()((() (energy intake) OR intake) OR food intake) OR appetite sensation) OR satiation) OR satiety response) OR satiety) OR satiety hormones) OR glucagon-like peptide-1) OR peptide YY) OR Ghrelin) OR leptin) OR cholecystokinin) OR motilin) OR motility) OR gastric emptying).

\section{Selection criteria}

Eligibility of each paper was assessed independently by two researchers (TK and DK) according to predefined criteria. Papers reporting the effects of post-oral delivery of noncaloric tastants on eating behavior (e.g., energy intake, GI
Table 1 Description of the PICOS criteria used to define the research question

\begin{tabular}{ll}
\hline Parameter & Description \\
\hline Participants & Healthy individuals \\
Intervention & Prototypical non-caloric tastants at least once \\
Comparison & Prototypical non-caloric tastants vs. placebo \\
Outcomes & Energy intake, GI symptoms and perceptions, and mechanisms of effect \\
Setting & Randomized controlled trials with a parallel or crossover design \\
Research question & What is the effect of post-oral delivery of non-caloric tastants on energy \\
& intake in healthy volunteers? Secondary: what is the effect of post- \\
& oral delivery of non-caloric tastants on GI symptoms and perceptions \\
& and what is the effect of post-oral delivery of non-caloric tastants on \\
& mechanisms of action in healthy volunteers \\
\hline
\end{tabular}


peptides, appetite sensations, GI motility, GI symptoms, brain signaling and other effects) were included. To investigate the function of gastrointestinal taste receptors, papers needed to properly bypass oral taste effects. Therefore, studies investigating delivery methods using catheters, capsules or other methods resulting in adequate masking of oral taste were included. Moreover, papers were excluded if they were reviews, comments, replies on an original paper, or abstracts without available full text. No limitations on publication date were set. Paper inclusion was agreed upon by both reviewers. A third reviewer (AM) was consulted with regard to inclusion in case of disagreement between the two reviewers.

\section{Outcome measures}

This systematic review looked at various aspects of eating behavior after post-oral delivery of non-caloric tastants. Outcome measures of interest were (1) energy intake, (2) GI symptoms and perceptions, and (3) mechanisms of effect.

\section{Data extraction}

Two reviewers (TK) and (DK) carried out the data extraction. Two authors were contacted to elaborate their data and they replied. Name of author, year of publication, country, sample size, age of subjects, BMI of subjects, tastants used, method of administration, energy intake, appetite sensations, GI symptoms, GI peptides, GI motility, and brain signaling in homeostatic and hedonic regions were abstracted and presented in tables. Principle summary measures are differences in means.

\section{Quality assessment}

Two independent reviewers (TK and DK) used the revised Cochrane risk of bias tool to assess risk of bias in randomized trials (RoB 2) to assess the quality of included papers [47]. The quality of the paper was assessed only once when a paper described multiple studies. A third reviewer (AM) was consulted in case of discordance between the two reviewers. The RoB 2 tool, assessing the quality of randomized controlled trials, consists of five domains covering bias arising from the randomization process, bias due to deviations from intended interventions, bias due to missing outcome data, bias in the measurement of the outcome, and bias in selection of the reported result. The scoring system assesses the risk of bias on these domains (low risk of bias, some concerns, high risk of bias). When an individual domain received score of a particular level of bias, overall risk of bias was determined to be at least as severe.

\section{Statistical analysis}

A meta-analysis was performed if at least two studies described the use of non-caloric tastants of the same basic taste on energy intake and clinical heterogeneity between studies was acceptable. Clinical heterogeneity was discussed by two independent reviewers (TK and DK). In case of discordance between these reviewers, a third reviewer (AM) was consulted. Meta-analyses were performed using a random effect model by the metaphor package in $\mathrm{R}$ (version 3.6.3) [48]. Energy intake in Kcal after tastants and control were pooled using the data provided by included studies. Sensitivity analyses were performed when same studies employed different doses of tastants in order for those subjects to not influence the results to a greater extent than subjects form other studies. The $I^{2}$ was used to quantitatively measure statistical heterogeneity between studies ( $p$ value $<0.05$ ).

\section{Data reporting}

Paper inclusion, exclusion, and reasons for exclusion are presented in a diagram (Fig. 1) according to the PRISMA statement for reporting a systematic review and meta-analysis.

\section{Results}

\section{Systematic approach to paper selection}

After removal of duplicates, a total of 11,271 abstracts were assessed, and 45 full texts were screened for eligibility (Fig. 1). A total of 19 papers, describing 25 studies met the inclusion criteria. Twenty-six papers were excluded for various reasons: abstract for a conference (13), review (5), study protocol (4), animal study (2), no adequate bypassing of oral taste receptors (1), no full text available (1). The flow-chart for screening and inclusion of papers is depicted in Fig. 1.

Supplementary Table 1 provides an overview of the results of the included papers.

\section{Quality assessment}

The results of the quality assessment are summarized in Fig. 2. Overall, papers scored decently on the risk of bias assessment. Bias arising from the randomization process was determined to raise some concerns by the majority of papers due to lacking information on the method of randomization. Most papers described randomization of subjects but provided no information on the method of randomization. 
Fig. 1 Flow chart of the selection process; from identification of possible eligible papers to papers included in this review and meta-analysis

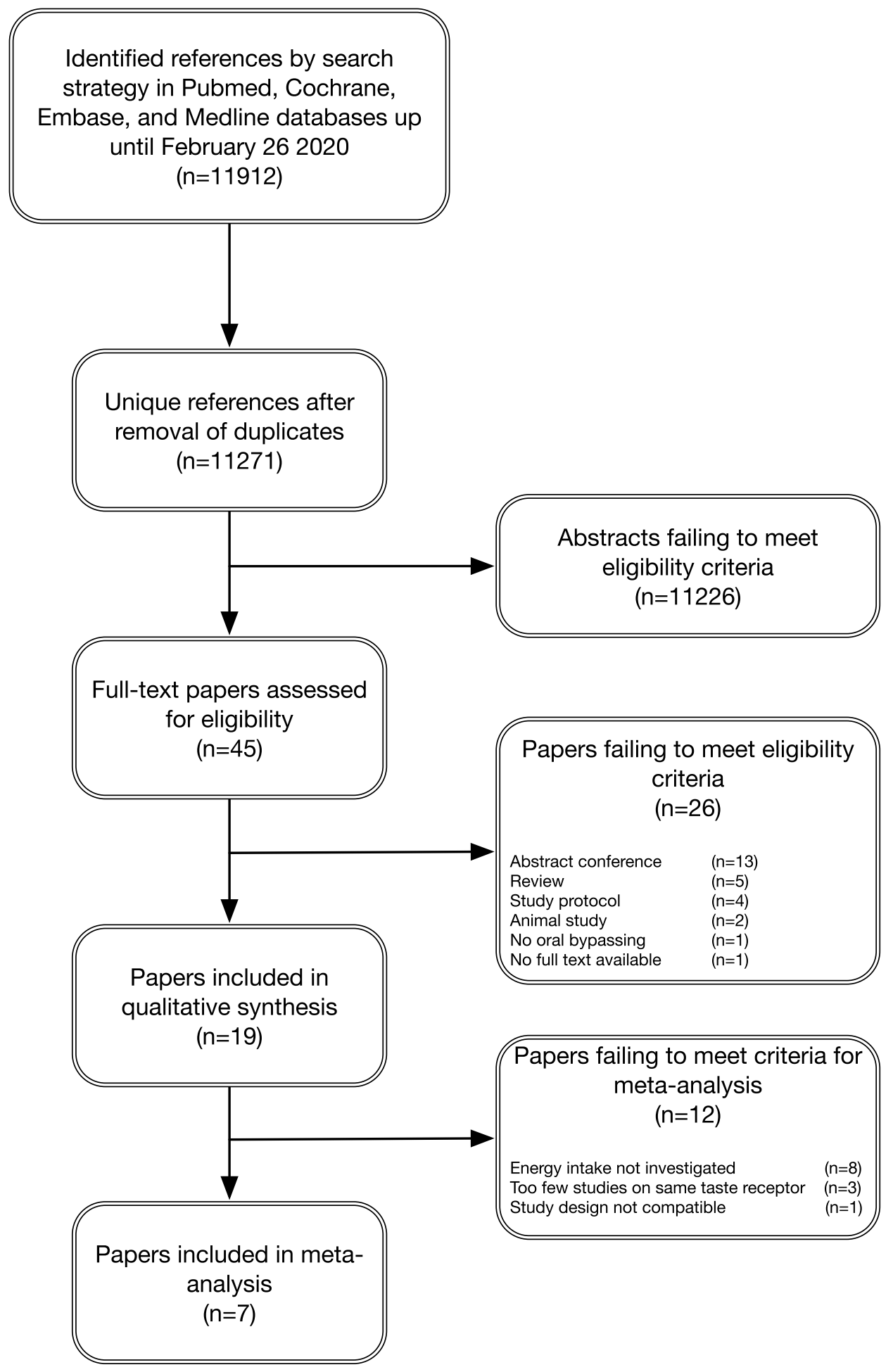

\section{Study characteristics}

\section{Study population}

The characteristics of the 25 studies described in 19 papers are summarized in Supplementary Table 1. All studies included healthy volunteers [27-45]. Most studies included volunteers with a normal BMI between 18 and $25 \mathrm{~kg} / \mathrm{m}^{2}$ [27-38, 40-42, 44, 45]. One study described inclusion of both subjects with a BMI between 18 and $25 \mathrm{~kg} / \mathrm{m}^{2}$ and subjects with a BMI greater than $30 \mathrm{~kg} /$ $\mathrm{m}^{2}$ [43]. One study described inclusion of subjects with 
Fig. 2 Risk of bias summary. Author's judgements broken down for the domains according to the revised tool to assess risk of bias in randomized trials (RoB 2)

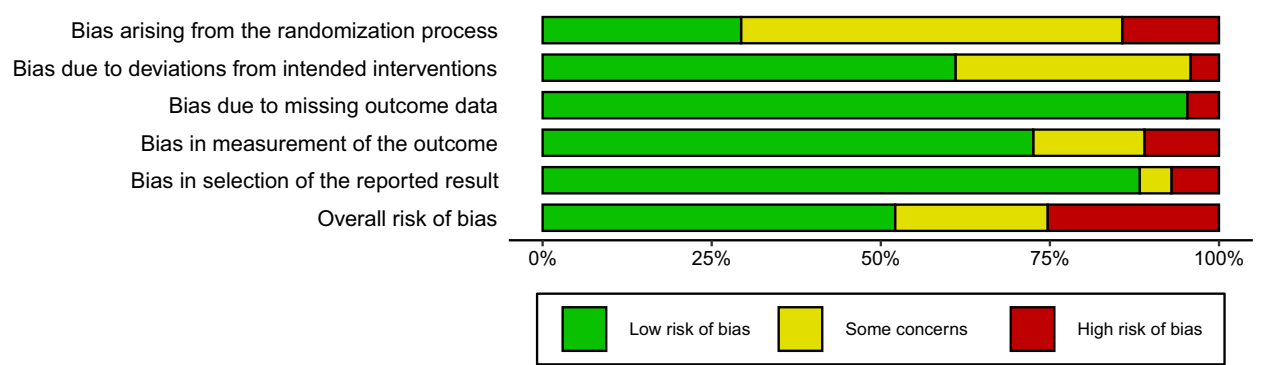

a BMI between 23 and $32 \mathrm{~kg} / \mathrm{m}^{2}$ [39]. Eleven studies described inclusion of both women and men [27, 28, 34-38, 40-43], four studies described inclusion of men only [29, 30, 44, 45], and four studies described inclusion of women only [31-33, 39].

\section{Tastants used}

Table 2 provides an overview of the tastants used by included studies and the ligand receptors that are activated per tastant.

\section{Sweet tastants}

Nine studies (reported on in eight papers) investigated postoral delivery of sweet tastants. Aspartame alone was used in three studies (two papers) [40, 44], one study used aspartame and saccharin [35], one study used aspartame, acesulfame potassium (Ace-K), and sucralose [41], one study used sucralose [36], one study used rebaudioside A (Reb-A) [42], one study used xylitol and erythritol [43], and one study used only Ace-K [38]. It should be noted that Reb-A, Ace-K, Saccharin, and sucralose are known to activate bitter taste receptors aside from sweet taste receptors. TAS2R4 and 14 are activated by Reb-A, TAS2R43 and 44 are activated by Ace-K, TAS2R43 and 44 are activated by saccharin, and TAS2R1, 4, 5, 7, 8, 10, 39, 41, 46 are activated by sucralose [49]. However, given their predominant sweet taste [50-52] and their main role as non-nutritive sweeteners, for this paper, they were described as sweet tastants.

\section{Bitter tastants}

Sixteen studies (12 papers) investigated post-oral taste delivery of bitter tastants. Six of these studies used quinine alone [27, 29-31, 33, 42], five studies (two papers) used

Table 2 Ligand receptors of the tastants described in the included studies. Ligand receptors for TAS2Rs adapted from BitterDB [49]

\begin{tabular}{ll}
\hline Tastant & Ligand receptors \\
\hline Aspartame & TAS1R2/TAS1R3 heterodimer \\
Saccharin & TAS1R2/TAS1R3 heterodimer, TAS2R43, TAS2R44 \\
Sucralose & TAS1R2/TAS1R3 heterodimer, TAS2R1, TAS2R4, TAS2R5, TAS2R7, TAS2R8, TAS2R10, \\
& TAS2R39, TAS2R41, TAS2R41, TAS2R46 \\
Ace-K & TAS1R2/TAS1R3 heterodimer, TAS2R43, TAS2R44 \\
Reb-A & TAS1R2/TAS1R3 heterodimer, TAS2R4, TAS2R14 \\
Xylitol & TAS1R2/TAS1R3 heterodimer \\
Erythritol & TAS1R2/TAS1R3 heterodimer \\
Naringin & N/A \\
Quinine & TAS2R4, TAS2R7, TAS2R10, TAS2R14, TAS2R39, TAS2R40, TAS2R43, TAS2R44, TAS2R46 \\
QHCl & TAS2R4, TAS2R7, TAS2R10, TAS2R14, TAS2R39, TAS2R40, TAS2R43, TAS2R44, TAS2R46 \\
DB & TAS2R4, TAS2R8, TAS2R10, TAS2R13, TAS2R39, TAS2R43, TAS2R46, TAS2R47 \\
Bitter secoiridoids (Gentiana lutea extract, & TAS2R1, TAS2R4, TAS2R39, TAS2R43, TAS2R46, TAS2R47, TAS2R50 \\
contains amarogentin) & \\
Raisin flavor & N/A \\
Sucrose octaacetate & TAS2R46 \\
Quassia extract & TAS2R4, TAS2R10, TAS2R14, TAS2R46, TAS2R47 \\
Amarasate extract & N/A \\
MSG & TAS1R1/TAS1R3 heterodimer \\
\hline
\end{tabular}

$T A S 1 R$ taste receptor $1, T A S 2 R$ taste receptor, $2 A c e-K$ acesulfame potassium, Reb-A rebaudioside A, N/A no data available, $Q H C L$ quinine hydrochloride, $D B$ denatonium benzoate, $M S G$ monosodium glutamate 
denatonium benzoate (DB) alone [28, 32], one study investigated quinine and naringin [35], one study used a bitter mixture consisting of raisin flavor, sucrose octaacetate, and quassia extract [39], one study used bitter secoiridoids [37], and one study used bitter New Zealand hop extracts [45]. Different bitter compounds activate different (combinations of) TAS2 receptor subtypes in humans $[49,53]$. However, most extensively investigated are quinine and denatonium benzoate, which both activate four of the same TAS2 receptor subtypes, among other subtypes. DB activates eight TAS2 receptor subtypes in humans (TAS2R 4, 8, 10, 13, $39,43,46$, and 47), whereas quinine activates nine subtypes of TAS2 receptor in humans (TAS2R 4, 7, 10, 14, 39, 40, 43, 44, and 46) [49, 53].

\section{Umami tastants}

Only one study investigated post-oral delivery of an umami tastant. Monosodium glutamate was used in this study [42].

\section{Combination of tastants}

Two studies investigated post-oral delivery of a combination of tastants (sweet, bitter, and umami). Both of these studies used quinine, Reb-A, and monosodium glutamate [34, 42].

\section{Comparators}

Most studies describe the use of a placebo. For studies using nasogastric, nasoduodenal or naso-duodenal-ileal delivery of tastants either tap water [32, 34, 35, 38, 41-43], saline [28-30,36], or milli-Q water [31,33] was used as a comparator. Most studies that used capsules to deliver the tastants used placebo capsules as a comparator [27, 39, 40, 45]. One study used a capsule to deliver tastants and used water without a capsule as comparator [44]. One study added microencapsulated bitter taste to a pudding and used only the coating as a comparator [37].

\section{Energy intake}

An overview of the studies describing effects of post-oral delivery of non-caloric tastants on energy intake is provided in Table 3.

\section{Sweet tastants}

Four studies (three papers) reported the effect of sweet tastants on energy intake [40, 42]. Two studies (one paper) showed a significant decrease of 138,150 , and $175 \mathrm{kcal}$ ( $p<0.05, p<0.01$, and $p<0.02$, respectively) of an ad libitum buffet meal after intragastric delivery of aspartame in various concentrations compared with placebo [40]. However, another study showed no effect on energy intake or macronutrient preferences during an ad libitum buffet meal after intragastric delivery of aspartame [44]. In line with this, one study failed to demonstrate a difference between Reb-A and placebo on ad libitum food intake intraduodenal delivery [42].

The data reported in two papers were not described in sufficient detail to use for pooling [40, 44]. The authors of these papers were contacted. Both authors responded and declared that raw data were not available anymore, since the studies were performed over 30 years ago. Therefore, these studies could not be pooled.

\section{Bitter tastants}

Eight studies showed the effect of post-oral delivery of bitter tastants on energy intake. Three of these described a decrease in energy intake after intragastric [33], intraduodenal [27], or post-oral delivery of bitter tastants [37]. On the other hand, five studies showed no effect on energy intake after gastrointestinal delivery of bitter tastants. However, most of these studies described a modest decrease in energy intake that did not reach statistical significance $[29,30,32$, 39, 42].

Iven et al. showed a decrease of $67.7 \mathrm{kcal}$ of hedonic eating after intragastric infusion of quinine compared with control [33]. Andreozzi et al. showed a decrease of $82 \mathrm{kcal}$ after an acid resistant capsule containing quinine compared with a placebo capsule [27]. Mennella et al. showed no significant decrease in lunch intake $(-88 \mathrm{kcal})$ after microencapsulated bitter secoiridoids compared with control, but a significant decrease of post-lunch energy intake $(-252 \mathrm{kcal})$ and $24 \mathrm{~h}$ energy intake ( $-340 \mathrm{kcal})$ [37].

Van Avesaat et al. showed a non-significant decrease of $44 \mathrm{kcal}$ after intraduodenal infusion of quinine compared with control [42]. Peters et al. investigated energy intake after a 2-week, two times daily consumed capsule containing a bitter mixture compared with control [39]. They showed a non-significant decrease of daily meal intake $(-109 \mathrm{kcal})$, daily meal intake including snacks $(-86 \mathrm{kcal})$, breakfast (-30 kcal), lunch (- $61 \mathrm{kcal})$, and dinner (-1 kcal). A nonsignificant increase of $41 \mathrm{kcal}$ on snacks only was found [39]. Deloose et al. showed that intragastric infusion of DB resulted in a non-significant decrease of $76 \mathrm{kcal}$ compared with control [32]. In one study, Bitarafan et al. showed a non-significant decrease in food intake following various doses of intraduodenally administered quinine compared with control $(-31 \mathrm{kcal}$ for $37.5 \mathrm{mg},-59 \mathrm{kcal}$ for $75 \mathrm{mg}$, and $-11 \mathrm{kcal}$ for $225 \mathrm{mg}$ ) [30]. In another study, Bitarafan et al. showed a non-significant increase in energy intake of $26 \mathrm{kcal}$ after intragastric administration $275 \mathrm{mg}$ of quinine, 


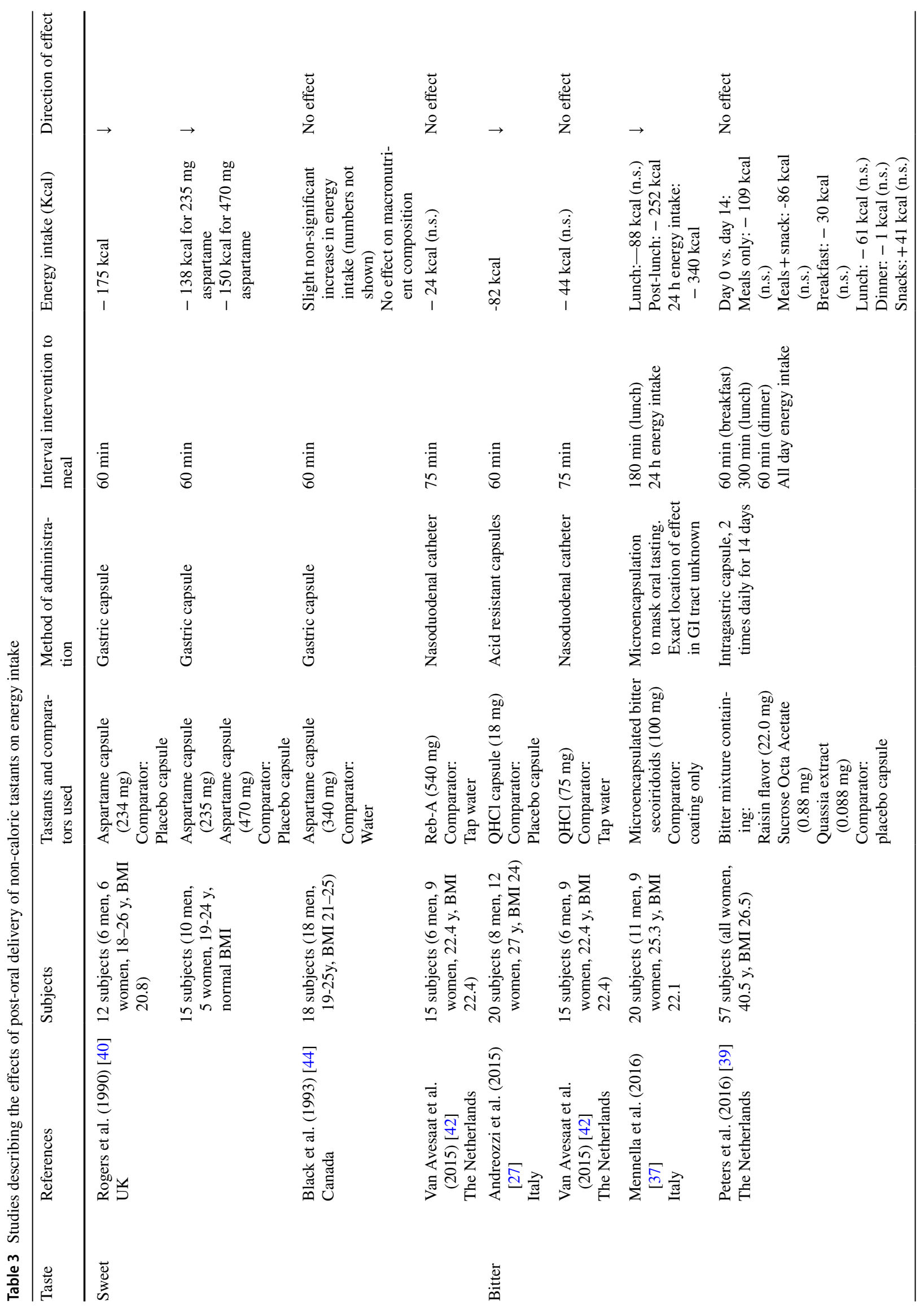




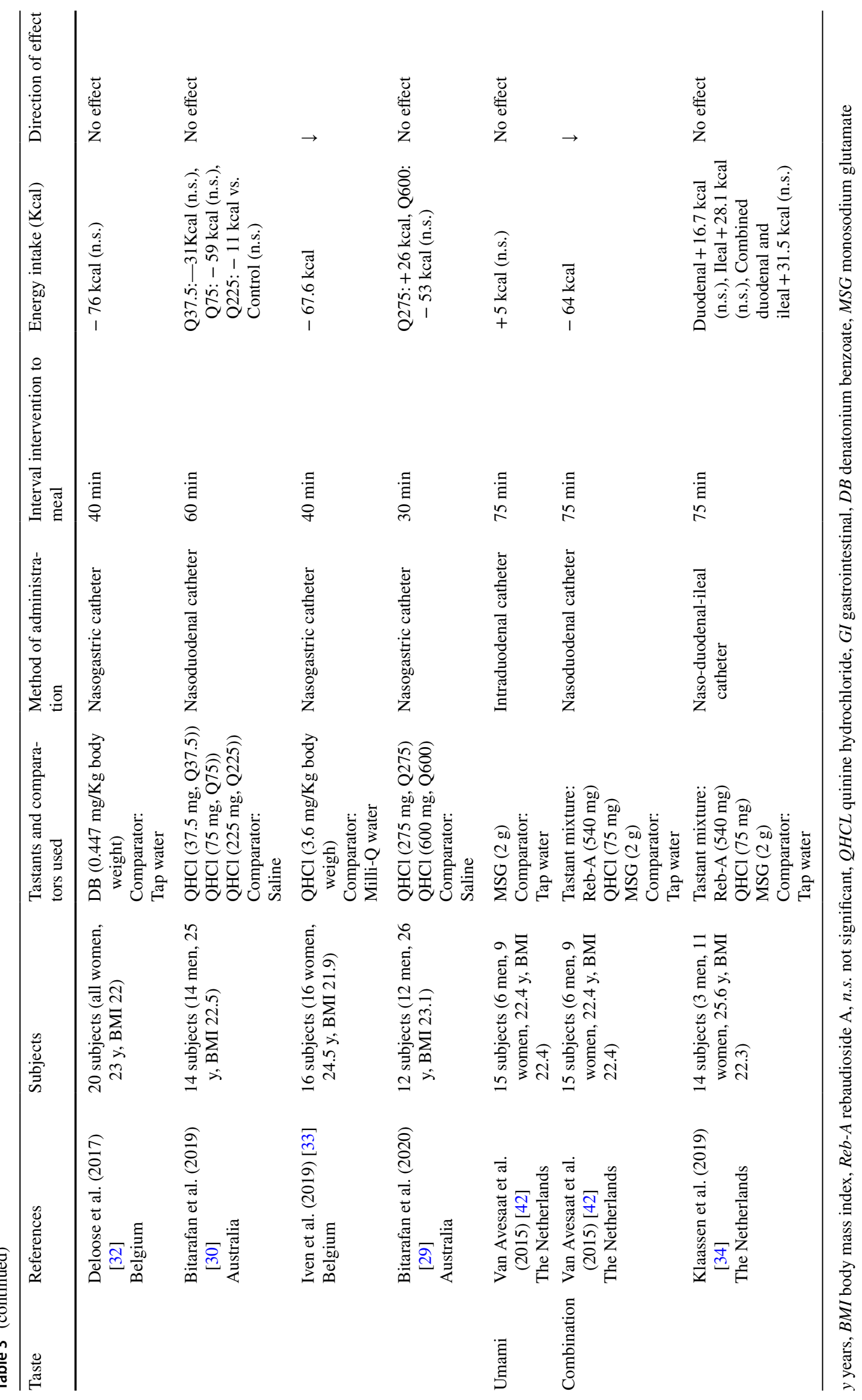


whereas intragastric administration of $600 \mathrm{mg}$ quinine showed a non-significant decrease of $53 \mathrm{kcal}$ [29].

Seven studies investigating the effect of gastrointestinal delivery of bitter tastants on energy intake could be pooled [27, 29, 30, 32, 33, 37, 42] and are depicted in Fig. 3. One study looked at total energy intake during the day as well as energy intake during the lunch [37]. Pooled effects were calculated with the outcome of lunch intake for this study to minimize clinical heterogeneity. One study investigating the effect of intragastric bitter tastant delivery on energy intake could not be pooled because the design employed in that study differed too much from the other designs [39]. Two studies employed various doses of $\mathrm{QHCl}$ in the same population $[29,30]$. In order for those subjects to not influence the results to a greater extent than subjects form other studies, the meta-analysis was performed for all the combinations of doses. The lowest dose for both studies is depicted in Fig. 3. Pooled effects show a significant reduction in caloric intake of $54.62 \mathrm{kcal}(95 \% \mathrm{CI}-78.54-30.69, p=0.0014)$. A sensitivity analysis was performed for all the combinations of doses employed by Bitarafan et al. and results are depicted in Supplementary Fig. 1. Decrease in caloric intake varies between 53 and $58 \mathrm{kcal}$ for the different combinations, all statistically significant $[29,30]$.

\section{Umami tastants}

Van Avesaat et al. showed no effect on energy intake after intraduodenal delivery of monosodium glutamate compared with placebo [42].

\section{Combination of tastants}

Van Avesaat et al. showed a significant decrease of energy intake of $64 \mathrm{kcal}$ after intraduodenal delivery of a combination of quinine, Reb-A and monosodium glutamate. A study conducted by the same research group showed no effects on energy intake after intraduodenal and/or intraileal delivery of the same tastant mixture [42]. These studies were not pooled, due to high clinical heterogeneity [34].

\section{Gl symptoms and perceptions}

An overview of the studies describing effects of post-oral delivery of non-caloric tastants on GI symptoms and perceptions is provided in Table 4.

\section{Sweet tastants}

Seven studies investigated the effects of gastrointestinal delivery of sweet tastants on appetite sensations. Five of these studies showed no effects on appetite sensations [35, 41-44]. One study showed that intragastric delivery of aspartame reduced desire to eat without influencing fullness [40]. Another study demonstrated a strong initial decrease in hunger and increase in satiety, with faster returns to baseline after intragastric delivery of Ace-K compared with control [38].

Three studies examined the effects of post-oral administration of sweet tastants on GI symptoms and other adverse events [38, 42, 43]. Wölnerhanssen et al. showed that intragastric administration of xylitol and erythritol leads to bloating and diarrhea in $70 \%$ and $60 \%$ of subjects, respectively [43]. Other studies reported no GI symptoms or adverse events $[38,42]$.

\section{Bitter tastants}

Five studies (four papers) showed that post-oral delivery of bitter tastants resulted in a decrease of hunger and prospective food consumption and an increase of satiation/satiety and fullness [28, 32, 33, 45]. However, six studies showed no effects on appetite sensations after post-oral delivery of bitter tastants [27, 29, 30, 35, 37, 42].

Seven studies examined the effects of post-oral delivery of bitter tastants on GI symptoms and/or adverse events. None of these reported side effects or adverse events [27, 29-33, 42].

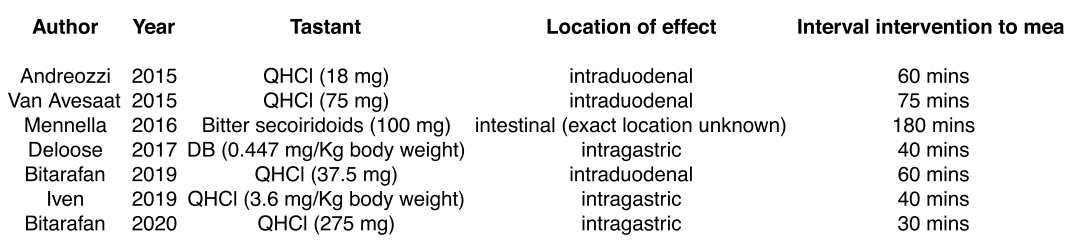

Prediction interval Heterogeneity: $I^{2}=0 \%, p=0.99$

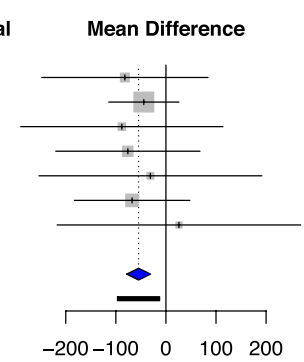

MD $95 \%-C l$ Weight

$-82.00[-247.90 ; 83.90] \quad 9.0 \%$ $-44.13[-114.02 ; 25.76] \quad 45.6 \%$ $-88.00[-289.73 ; 113.73] \quad 6.1 \%$ $-76.00[-219.88 ; 67.88] 11.8 \%$ $-31.00[-253.27 ; 191.27] \quad 5.1 \%$ $-67.60[-182.72 ; 47.52] 18.2 \%$ $26.00[-217.01 ; 269.01] \quad 4.2 \%$ $-54.62[-78.54 ;-30.69] 100.0 \%$ $[-96.64 ;-12.59]$

Fig. 3 Forest plot for pooled mean difference in energy intake after bitter components versus placebo. For the papers Bitarafan et al. [30] and Bitarafan et al. the lowest dose is depicted. $\mathrm{QHCl}$ quinine hydrochloride, $\mathrm{DB}$ denatonium benzoate 


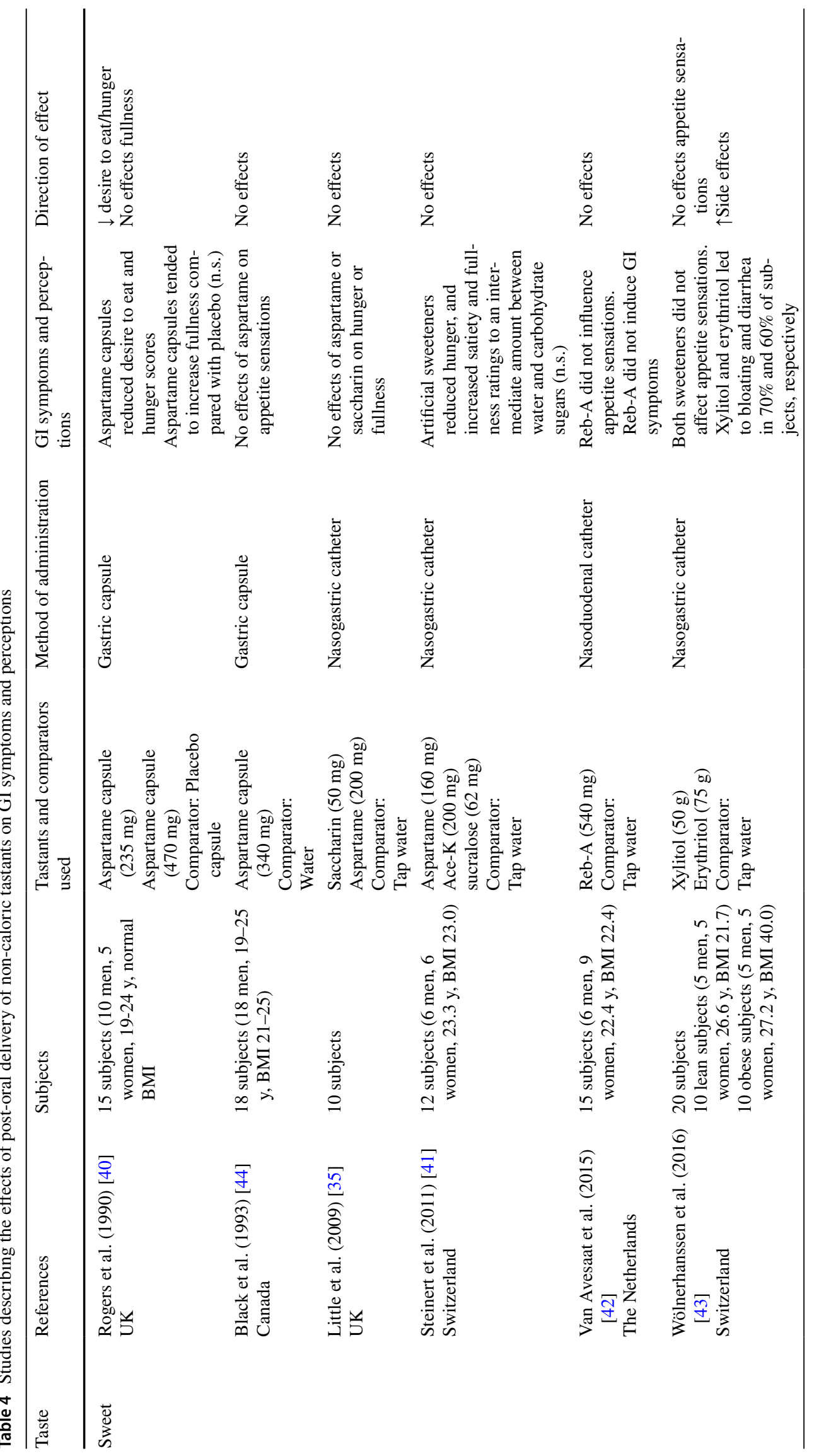




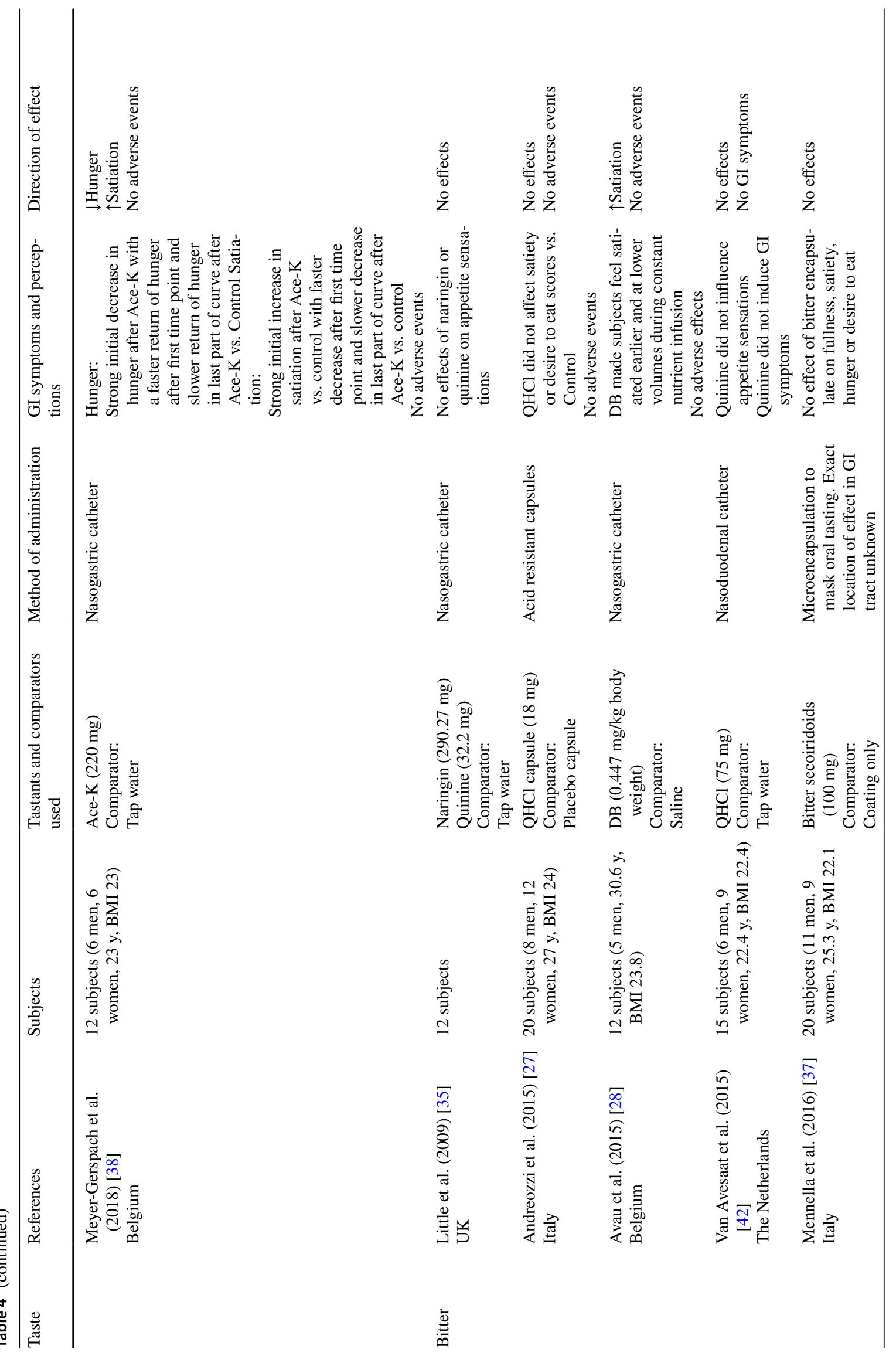




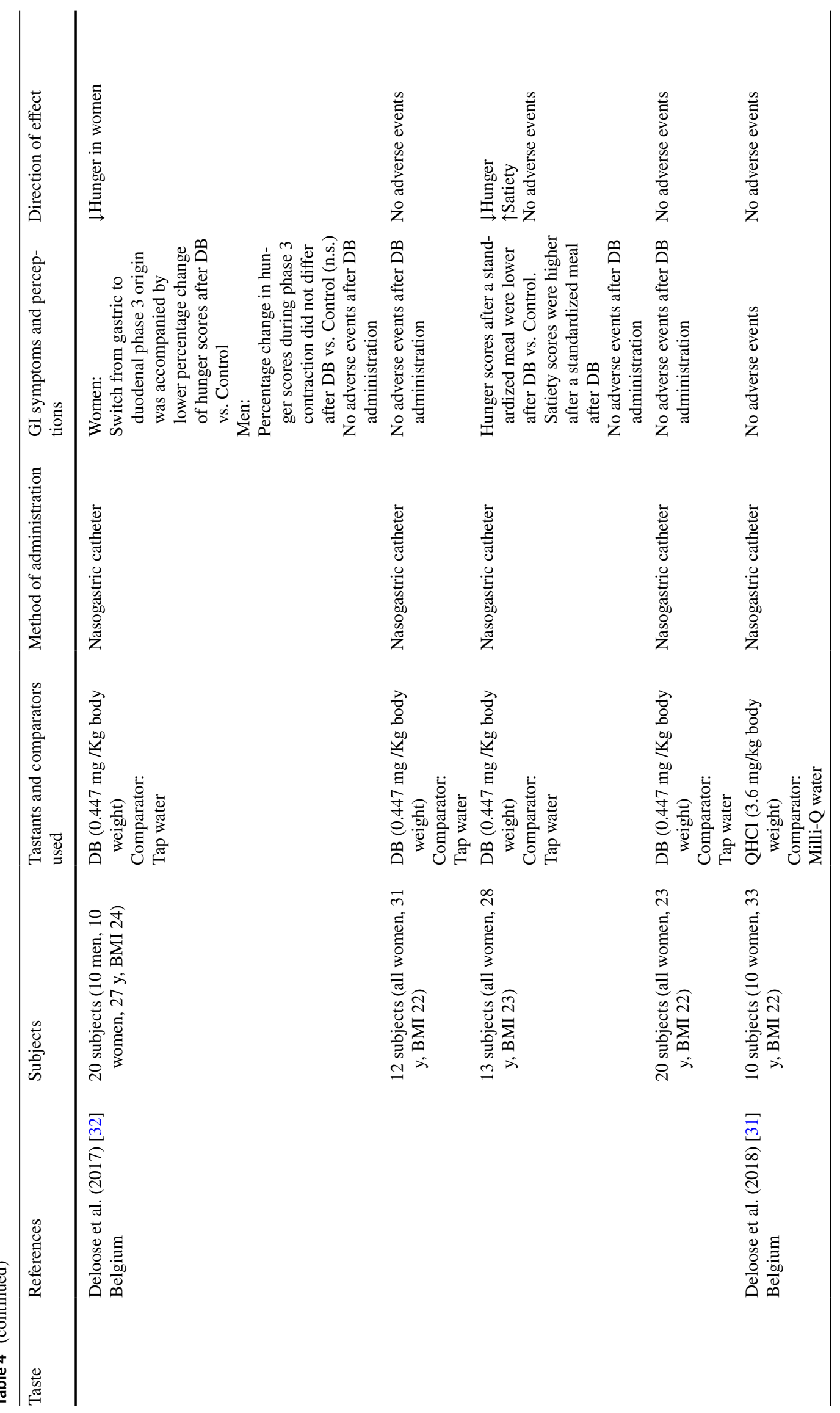




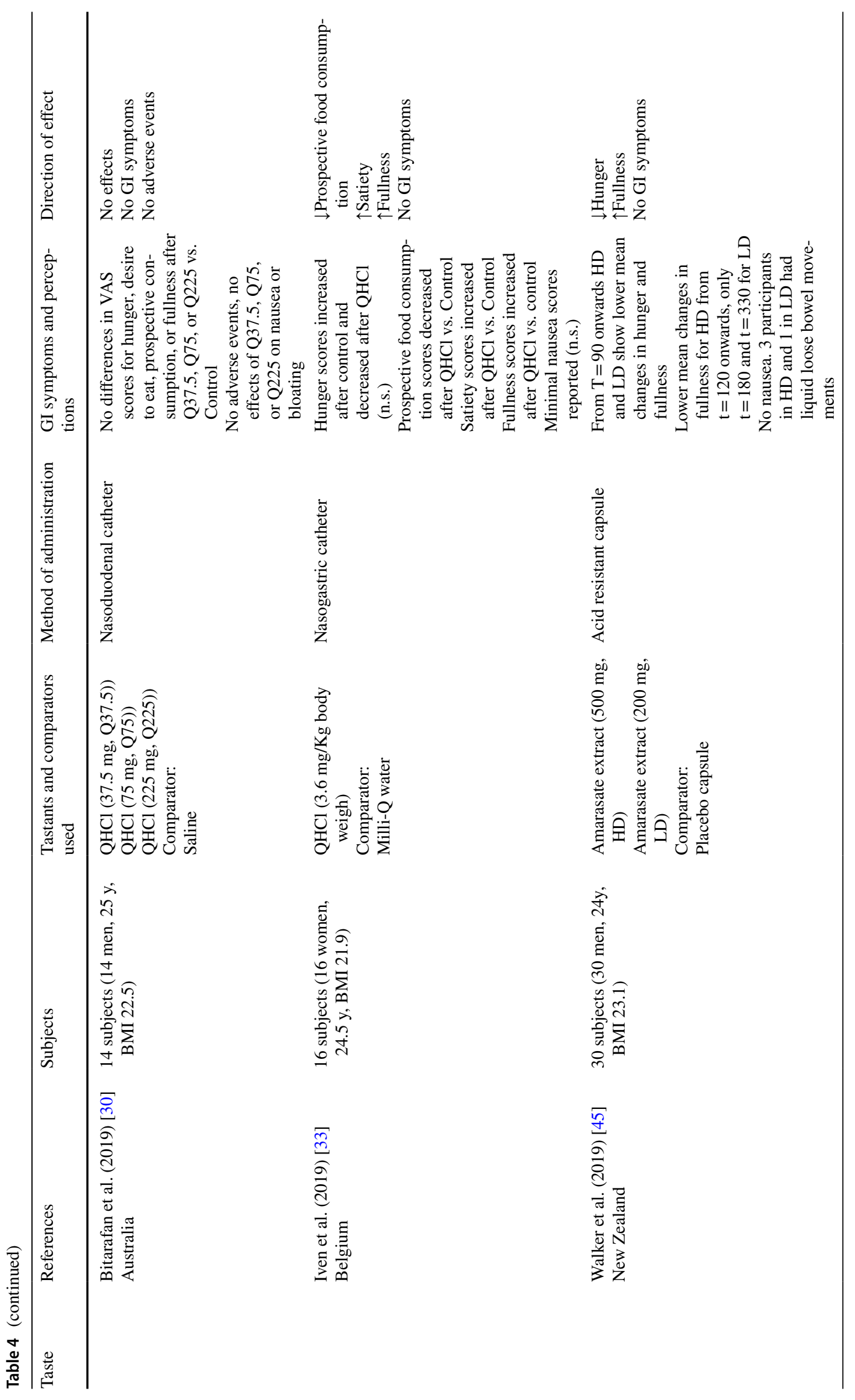




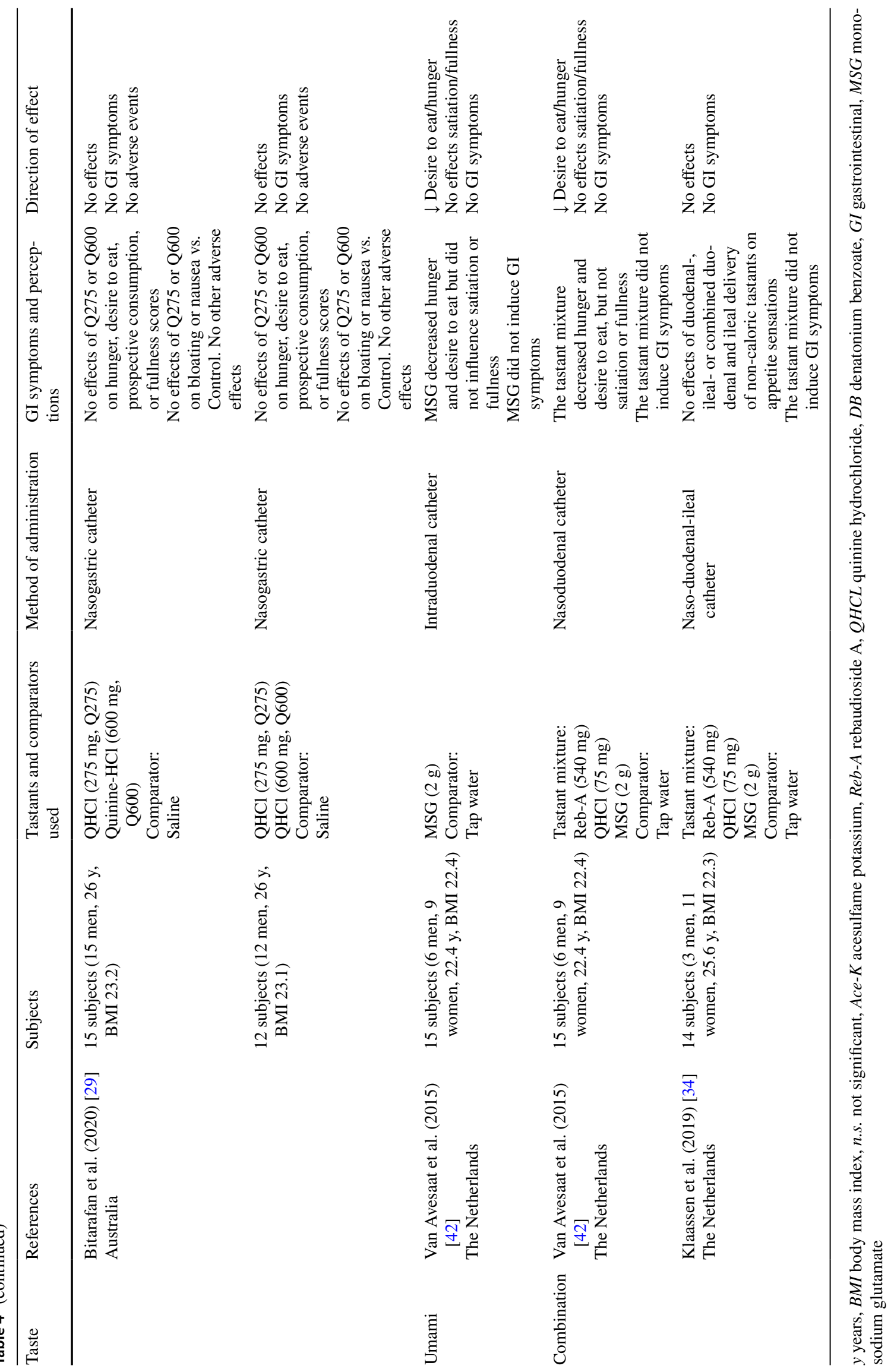




\section{Umami tastants}

One study described that post-oral delivery of umami decreased the desire to eat and hunger, without influencing satiation, fullness or GI symptoms [42].

\section{Combination of tastants}

Two studies described the effects of post-oral delivery of a combination of sweet, bitter and umami tastants on appetite sensations. One study described a decrease of desire to eat and hunger, whereas satiation and fullness were not attenuated [42]. The other study showed no effects on appetite sensations [34].

No GI symptoms or adverse events after post-oral delivery of this combination of sweet, bitter, and umami tastants were reported [34, 42].

\section{Mechanisms of effect}

An overview of the studies describing effects of post-oral delivery of non-caloric tastants on the mechanisms of effect involved in regulating eating behavior is provided in Table 5 . The mechanisms of interest were GI peptide release, GI motility, and brain signaling.

\section{Sweet tastants}

One study described a drop in intragastric pressure after intragastric administration of Ace-K [38]. Intragastric administration of xylitol and erythritol also resulted in slower gastric emptying [43]. However, another study showed no changes in gastric emptying after intragastric administration of saccharin or aspartame [35].

Five studies investigated the effects of post-oral delivery of sweet tastants on GI peptides [36, 38, 41-43]. Four of these showed no effects on GI peptide plasma levels [36, 38, $41,42]$. One study described that intragastric administration of xylitol and erythritol increases plasma CCK, GLP-1, and glucose [43].

\section{Bitter tastants}

Eight studies (seven papers) investigated the effects of postoral delivery of bitter tastants on GI motility [27-32, 35]. Two of these showed a decrease in gastric phase 3 contractions after intragastric delivery of bitter tastants [31, 32]. One study described a relative increase in intragastric pressure after DB compared with placebo [28]. Four studies showed no effect of post-oral delivery of bitter tastants on gastric emptying [27, 29, 32, 35]. Another study showed no effect of intraduodenal delivery of quinine on antral, pyloric or duodenal pressure waves [30].

One study showed that intragastric delivery of quinine resulted in increased brain activity in homeostatic and hedonic brain regions [33].

Eight studies examined the effects of post-oral delivery of bitter tastants on GI peptides [27, 29-33, 37, 42]. Two studies showed that post-oral delivery of bitter tastants did not result in changes in GI peptides [30, 42]. One study showed an initial effect of quinine on plasma insulin, but not on plasma glucose, glucagon or GLP-1. However, a decrease of glucose and an increase of insulin was found after a standardized nutrient drink following quinine administration [29]. Another study showed a decrease in GLP-1 30 min after intervention but no effects on other GI peptides, nor an overall intervention effect on plasma GLP-1 levels [37]. Three studies showed a decrease in motilin and/or ghrelin after intragastric delivery of bitter tastants [31-33]. Only one study showed an increase of CCK after intraduodenal delivery of quinine [27].

\section{Umami tastants}

One study investigated the mechanisms of effect of post-oral delivery of monosodium glutamate, showing no changes in GI peptides (CCK, GLP-1, and PYY) after intraduodenal administration of MSG [42].

\section{Combination of tastants}

Only one study investigated the effect of post-oral delivery of a combination of tastants. No effect of intraduodenal administration of a combination of sweet, bitter and umami tastant mixture on plasma CCK, GLP-1, or PYY was found [42].

\section{Discussion}

In this systematic review and meta-analysis, the currently available data on the effects post-oral delivery of noncaloric tastants has been evaluated. This review shows that the effects of post-oral delivery of non-caloric tastants on eating behavior are inconclusive and inconsistent thus far.

\section{Tastants: sweet, biter and umami}

Most studies described the effects of post-oral delivery of sweet $[35,36,38,40-44]$ or bitter $[27-33,35,37,39,42$, 45] stimuli. Only one study used an umami stimulus [42] and two studies described the effects of a tastant mixture [34, 42]. It has been hypothesized that taste can predict the type of food that is being ingested (i.e., bitter for potential toxic substances, umami for glutamate and sweet for saccharides) [8], although this theory is probably an oversimplification 


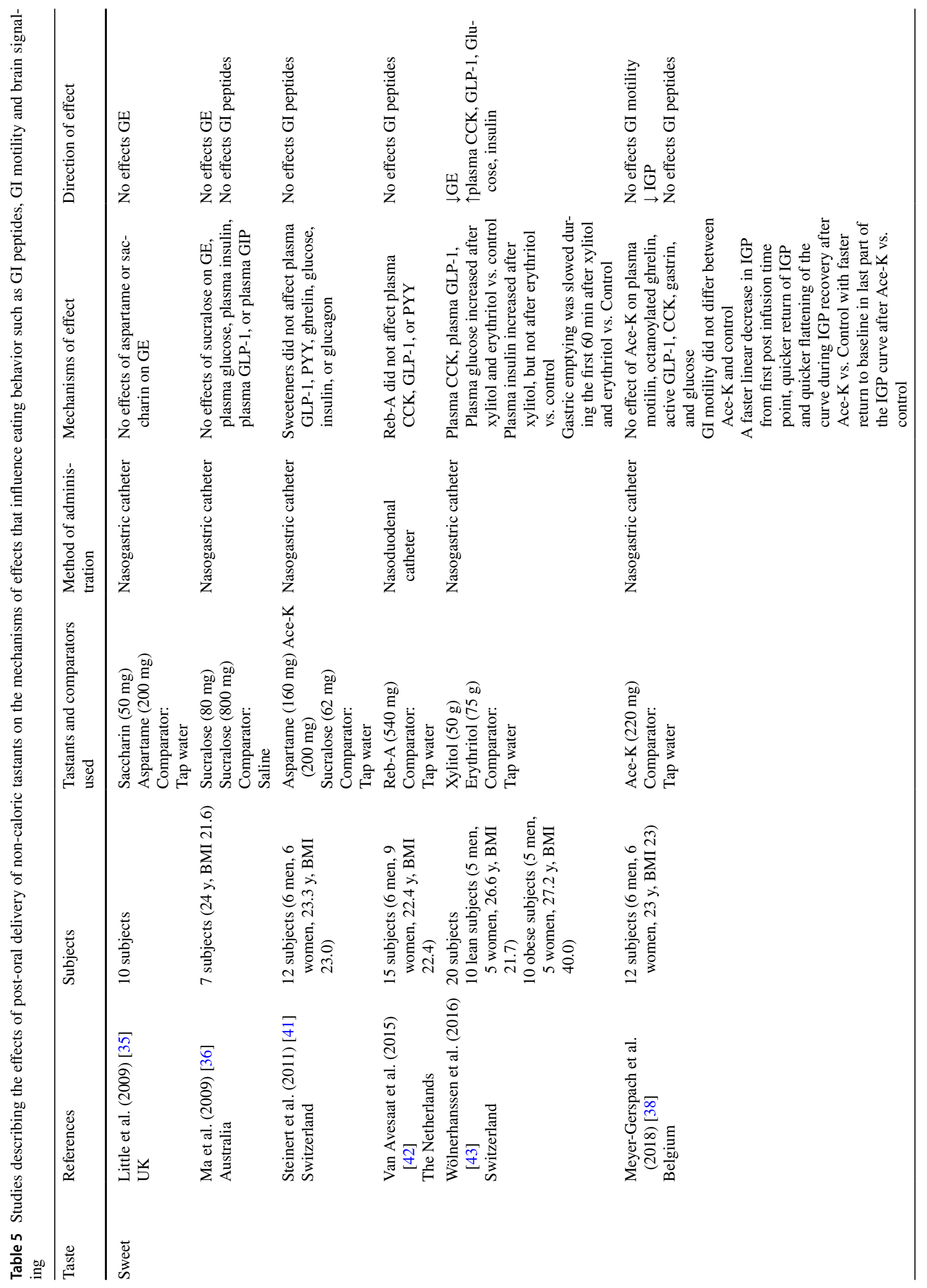




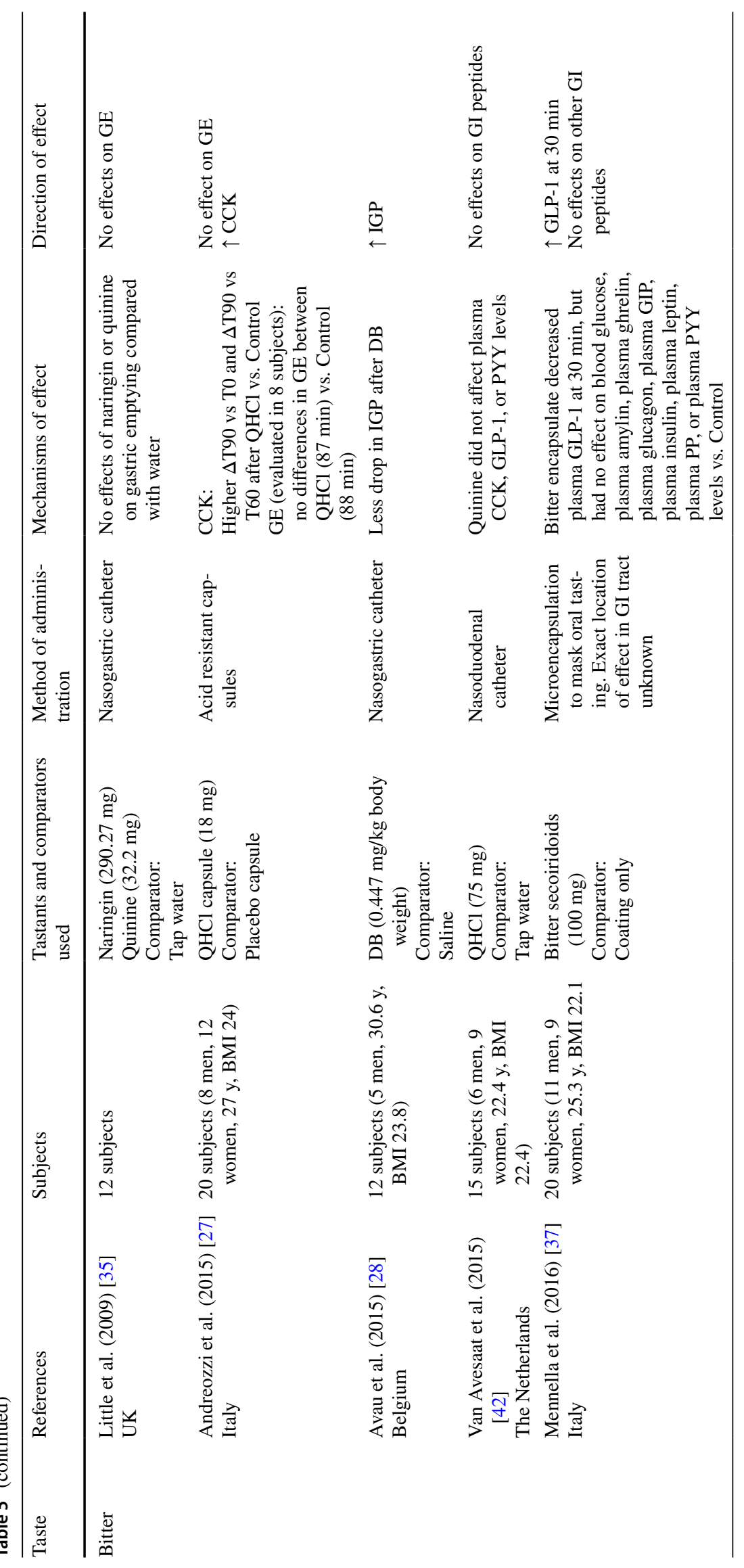




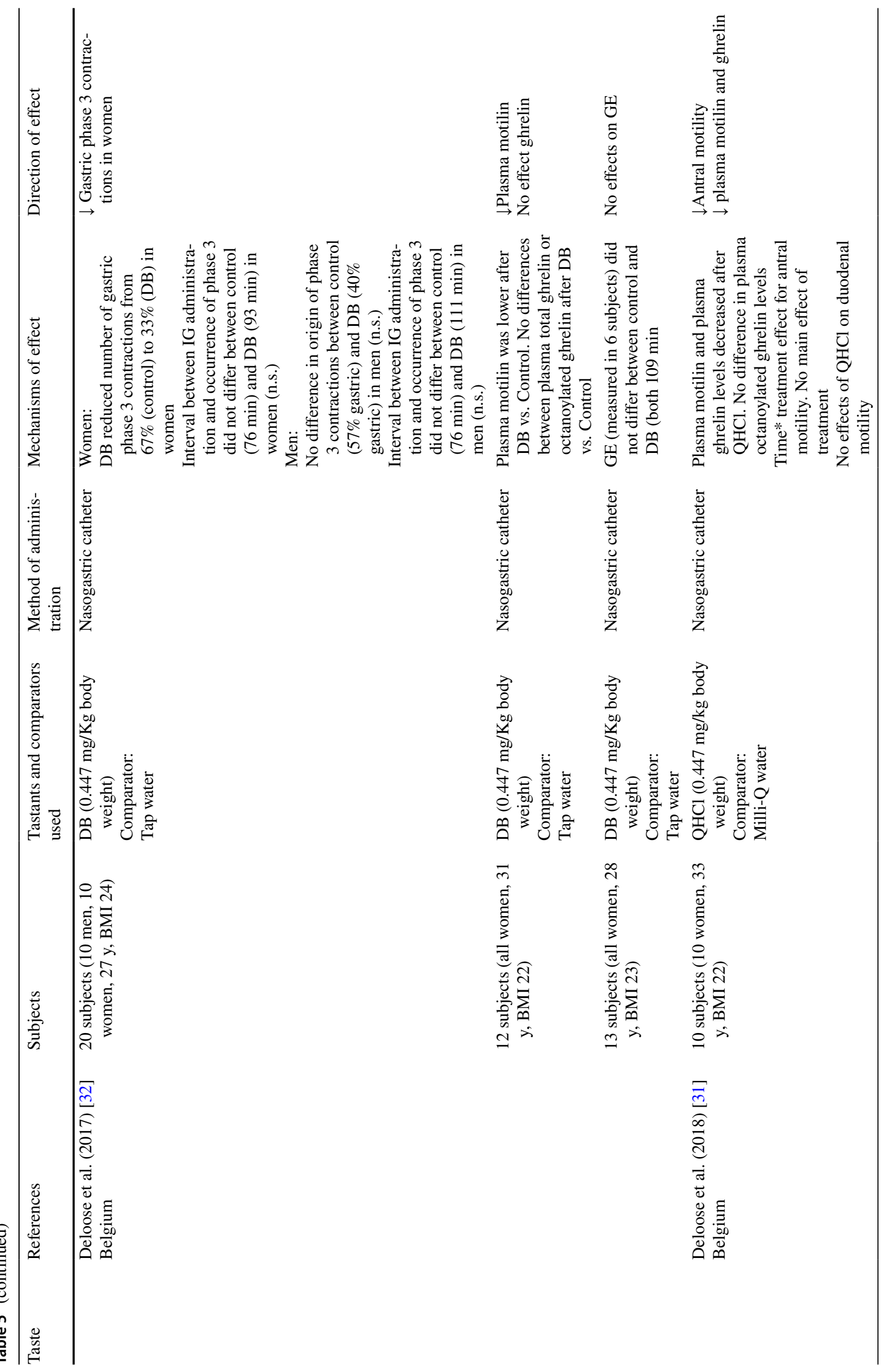




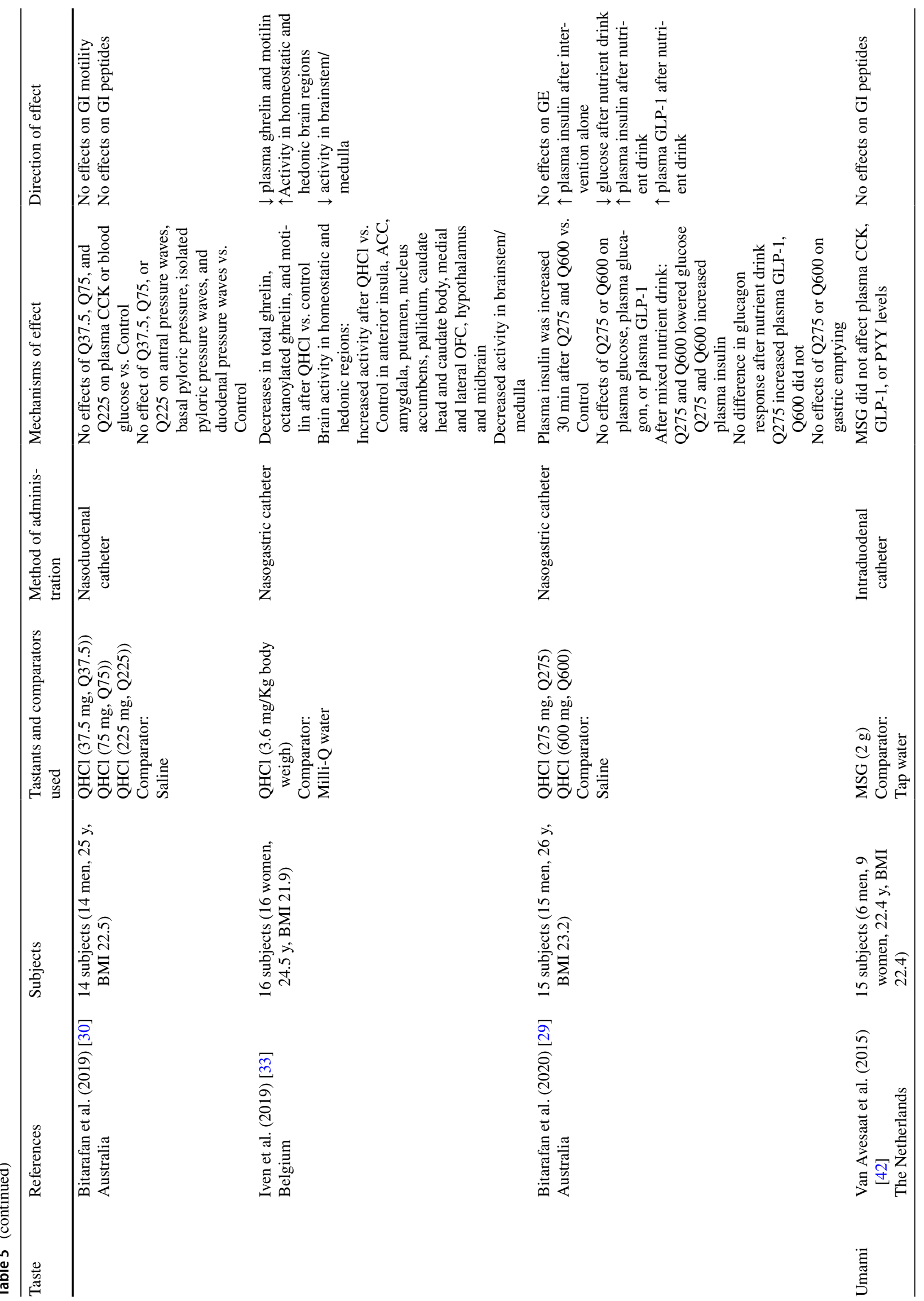


and does not sufficiently reflect the complexity of the underlying biological responses. According to traditional beliefs, carbohydrates are considered as fuel for the human body [54], whereas one wants to avoid toxic substances [55]. Therefore, it is conceivable that most researchers hitherto have generally focused on sweet and bitter substances. However, umami taste is a predictor of amino acids. Up to now, little is known about solely post-oral effects of umami taste, although it has been widely accepted as a basic taste since the discovery of umami taste receptors in 2002 [56, 57]. However, more data are available on oral delivery of umami stimuli. Oral delivery of umami stimuli has been shown to elicit a GLP-1 response [58, 59]. Moreover, adding MSG to a novel flavor is able to condition liking for that flavor [60]. Furthermore, Dermiki et al. showed that adding MSG to novel flavored soups resulted in increased food intake in elderly subjects without eliciting increased liking [61]. Given the effects of oral MSG on food liking, food intake, and GI peptides, the effect of post-oral delivery of umami tastants should be further elucidated.

\section{Energy intake}

This review and meta-analysis clearly shows that the most potent stimuli to influence eating behavior and reduce food intake are the bitter substances. The obvious explanation for this is the innate aversion for bitter taste [62]. That is, delivery of solely bitter tastants, in the absence of other flavors, would result in a warning signal with the intention to stop the intake of that particular substance. However, it should be noted that several studies show that this negative affective response to bitter can be decoupled by, for instance, the positive response to caffeine $[9,10]$. This process is called flavor-consequence learning [63]. Moreover, Higgins et al. showed an increase in pale ale intake in individuals with increased bitter perception [64]. This indicates that, over the years, humans have learned to appreciate bitter tastes, mainly when combined with other flavors (i.e., liking for black coffee and beers).

The question, however, arises whether any such mechanism would also hold true for post-oral taste receptor stimulation.

Data on post-oral delivery of sweet tastants are limited to three studies showing contradictory results [40, 42, 44]. Interestingly, more data are available on the effect of oral consumption of non-caloric sweeteners on energy intake. A review and meta-analysis by Rogers et al. that also included studies using oral stimulation showed a reduction of energy intake after consumption of low caloric sweeteners when compared with sugar consumption but not when compared to consumption of water in a short-term setting [65]. Since there is a preference for sweet foods and beverages in humans, further research to investigate the effects 
of post-oral delivery of sweet tastants on energy intake is warranted.

Eight studies described effects on energy intake after post-oral delivery of bitter tastants. These studies show a modest decrease in energy intake following post-oral delivery of bitter tastants [27, 29, 30, 32, 33, 37, 39, 42]. These decreases in energy intake varied from 11 to $88 \mathrm{kcal}$ in the acute setting to $340 \mathrm{kcal}$ on a daily basis. Pooled effects of post-oral delivery of bitter tastants show a significant decrease of $54 \mathrm{kcal}$ compared with placebo in the acute setting. In itself, a reduction of $54 \mathrm{kcal}$ in a single meal is rather small. However, in case this reduction in energy intake can be replicated several times daily over a longer period of time, this may indeed lead to a daily caloric deficit and subsequent weight loss. It should be noted, however, that these modest effects on caloric intake point towards a role in weight control rather than weight loss.

\section{Gl symptoms and perceptions}

Based on the included papers, no clear effects of post-oral delivery of non-caloric tastants on appetite sensations was found. However, it must be noted that appetite sensations are rarely measured as a primary outcome. Consequently, most studies might not have been adequately powered to detect differences in appetite sensations. Therefore, interpretation of these results should be done with care.

Interesting to point out is the finding of Deloose et al. showing a longer sustained satiation in response to bitter after a standardized test meal [32]. This observation indicates that adding a bitter tastant to a caloric carrier could result in a delay until the next meal. Such a combination could result in a decrease in snacking in between meals. In line with this, Mennella et al. found in their study a reduction in caloric consumption during the day, after intake of a breakfast containing an encapsulated bitter mixture leading to prolonged satiation [37].

Only one study investigated the effect of post-oral delivery of an umami stimulus. A decrease in desire to eat and hunger was found [42].

\section{Safety}

According to the studies described in this review, noncaloric tastant administration is considered to be safe. One study reported side effects after administration of high doses of xylitol and erythritol, which was not surprising given the doses employed [43]. Other studies showed no GI-symptoms or other side effects after post-oral delivery of non-caloric tastants [27-34, 38, 42, 45]. It should be taken into account that, almost all studies focused on acute effects of post-oral delivery of non-caloric tastants and not on prolonged, daily administration.
The United States Food and Drug Administration (U.S. FDA) issues an acceptable daily intake (ADI) for various food components, including tastants. For example, the U.S. FDA issued a code of regulations stating soft drinks are allowed to contain 83 parts per million quinine [66]. Moreover, a systematic review describing the use of quinine to treat muscle cramps showed an increase of gastrointestinal complaints, headache and tinnitus after daily intake of 200-500 mg of quinine for 3 days up to several weeks [67]. Even more, the Medicines and Healthcare products Regulatory Agency (MHRA) issued a reminder on the dose-dependent effects on the QT interval [68]. Therefore, prolonged intake of high doses or combination with other drugs that prolong the QT interval should be avoided. Interestingly, in studies included in this review, the dose of the bitter tastant quinine ranged from 18 to $600 \mathrm{mg}[27,29-31$, 33-35, 42]. This did not result in side effects in the studies investigating the acute effects of these compounds. However, when applying quinine daily to prevent obesity, the maximum dose should be carefully considered. This should be considered in future study protocols.

\section{Mechanisms of effect}

Gastric emptying was delayed by high doses of xylitol and erythritol [43]. However, other studies showed no effect of post-oral delivery of non-caloric tastants on gastric emptying [27, 29, 32, 35]. Therefore, gastric emptying does not seem to be attenuated by post-oral delivery of non-caloric tastants.

GI motility appears to be attenuated as one research group has consistently found gastric motility and the GI peptides motilin and ghrelin to be affected by post-oral delivery of non-caloric tastants [28, 31-33]. Moreover, this research group recently published a review that elaborated the role of motilin as a regulator of hunger and food intake in humans [69], which indicates motilin as a possible target in combating the obesity epidemic. These interesting data are awaiting replication by other research groups.

Four studies showed increased CCK and/or GLP-1 levels after post-oral delivery of non-caloric tastants [27, 29, 37, 43]. Other studies that investigated these traditional satiety peptides did not find any effect of post-oral delivery of noncaloric tastants [30, 36, 38, 42]. This raises the question whether the focus should shift from more traditional satiety peptides towards motilin and/or ghrelin. It must be noted that all studies reported on plasma levels of GI peptides, pointing to systemic effects. Up to now, it is still unclear what the effect of taste receptor activation is on local secretion of GI peptides. It is conceivable that GI peptides are elevated at a splanchnic level or that they exert a more local or paracrine effect. 
Only one study investigated brain signaling after postoral delivery of non-caloric tastants. These authors found an increase in activity in homeostatic and hedonic brain regions and a decrease of activity in the brain stem and medulla after intragastric delivery of quinine [33]. These are interesting findings, since these data suggest additional mechanisms of effect of post-oral delivery of non-caloric tastants on eating behavior. It remains to be further elucidated whether these changes are mediated by orexigenic GI peptides.

\section{Implications of present data}

In this review and meta-analysis, we have summarized the current knowledge on the effects of non-caloric tastants on energy intake. Using non-caloric tastants to reduce energy intake could provide a useful tool to combat the obesity epidemic.

Specifically, the use of bitter tastants appears to be promising. It is important to note that most studies described in this review have been performed in healthy adults with a normal BMI or in slightly overweight healthy adults. In several studies blunted postprandial levels of PYY [70, 71] and GLP-1 [72-74] were observed in obese subjects, and reductions in plasma CCK after weight loss $[75,76]$. This points to alterations in the sensitivity of various receptors to GI peptides and in the magnitude of peptide secretion in obesity. Non-caloric tastants, because of their modest reduction in caloric intake, appear to be more suitable as a weight control intervention in a population that is worried about but has not yet gained excess weight.

This review and meta-analysis clearly illustrates the potential of bitter tastants in reducing caloric intake. However, several weaknesses of the currently available data should be elucidated. First, data are lacking uniformity. Most studies were underpowered: only small numbers of subjects have been included. Second, different study designs have been employed, making it difficult to compare results between various publications. An important variable with respect to energy intake reduction is the varying time interval between post-oral delivery of non-caloric tastants and meal intake. These intervals varied among studies between $30 \mathrm{~min}$ and $5 \mathrm{~h}$ but usually an interval around $60 \mathrm{~min}$ was chosen. The optimal interval between intervention and ad libitum meal is currently unknown, but standardization is necessary.

Third, most of the studies included in this review described the acute effects of post-oral delivery of noncaloric tastants on eating behavior. Only two studies described energy intake during the day [37,39] and only one of those described an intervention period of 2 weeks [39]. Therefore, data on the long-term effects of post-oral delivery of non-caloric tastants are lacking. Consequently, it is unknown whether adaptation to the effects occurs. A fourth limitation is the lack of knowledge on the effects of post-oral delivery of umami tastants on eating behavior, as this was described in only one paper [42]. Fifth, only one study investigated several target locations in the GI tract [34]. Sixth, based on the present data it is unknown which bitter stimulus elicits the greatest effect on energy intake. Most studies described the use of either $\mathrm{QHCl}$ or DB.

\section{Future perspectives}

To evaluate the effects of gastrointestinal delivery of noncaloric tastants on eating behavior, future studies should preferably standardize study design and doses of tastants. First, standardization could be achieved by creating consensus from the lead experts in the field. Second, mechanisms of effect should be more thoroughly investigated. For this, more research on the effects of post-oral delivery of noncaloric tastants on GI motility and systemic and local GI peptides secretion is needed. Based on the current data, we propose to focus on motilin and gastric motility. Third, compared with other tastants, knowledge on the effects of umami tastants is lacking. Therefore, the effects of post-oral delivery of umami tastants should be further elucidated. Fourth, taste receptors are expressed throughout the entire GI-tract [19-22]. The most appropriate location(s) for tastant delivery to modulate eating behavior is unknown. More research investigating delivery of tastants in different locations in the GI-tract is needed. Fifth, the optimal dose of tastants to exert an effect on eating behavior is unknown. Studies should focus on finding the balance between the maximum possible effect without occurrence of side effects. Sixth, it should be investigated which bitter stimulus elicits the largest effect on energy intake. For this, studies should compare different bitter stimuli. We propose to focus on $\mathrm{QHCl}$ and $\mathrm{DB}$, as most data are available on these bitter stimuli and both stimuli activate a wide range of bitter receptors. Lastly, when all the foundations are laid out, the field should move towards implementation of the successful interventions in battling the obesity epidemic. For this, the longer-term effects of post-oral delivery of non-caloric tastants on energy intake and ultimately body weight control should be investigated.

\section{Conclusion}

The current data show that, among tastants, bitter compounds are most effective in influencing eating behavior. Energy intake, in the acute setting, decreased modestly after post-oral delivery of bitter tastants. This highlights the potential preventive role of bitter tastants in battling the obesity epidemic. However, there are still several gaps in knowledge, for which recommendations have been provided. 
Systematically addressing these issues is warranted and worldwide collaboration could provide a welcome solution.

Supplementary Information The online version contains supplementary material available at https://doi.org/10.1007/s00394-021-02485-4.

Acknowledgements We thank all the volunteers for participating in the included studies of this review and meta-analysis.

Author contributions All authors contributed to the study conception and design. Literature search and data analyses were performed by TK and DK. The first draft of the manuscript was written by TK and all authors commented on previous versions of the manuscript. All authors read and approved the final manuscript.

Funding This research received no specific grant from any funding agency, commercial or not-for-profit sectors. Affiliation 2 is supported by the Province of Limburg, The Netherlands.

\section{Compliance with ethical standards}

Conflict of interest The researchers were involved in conducting two of the included studies: reference 26 (T.K., D.K., F.J.T., A.A.M.M.) and reference 34 (F.J.T., A.A.M.M.). For investigator-initiated study (reference 26), Will Pharma SA has received governmental funding (Subsidie MKB Innovatiestimulering Topsectoren, MIT) and covered all relevant costs related to the execution of that study. T.K. received a salary from Will Pharma SA as part of the 'Subsidie MKB Innovatiestimulering Topsectoren' (MIT) for the period related to the execution of that study (reference 26). D.K. and A.A.M.M. have received an unrestricted grant from Will Pharma SA for the execution of a study unrelated to the present study (peppermint oil in IBS). D.K. and A.A.M.M. have received grants from ZonMw, The Netherlands Organisation for Health Research and Development, to evaluate efficacy of peppermint oil in IBS, hypnotherapy in IBS, and the efficacy of nortriptyline in functional dyspepsia. D.K. and A.A.M.M. have received research funding from Allergan and Grünenthal on IBS topics. D.K. has received research funding from the Dutch Foundation for Gastroenterology (Maag-Lever-Darmstichting) for IBS and United Europe Gastroenterology (UEG) for fecal incontinence. A.A.M.M. has given scientific advice to Bayer (topic: IBS), to Kyowa Kirin (topic: constipation), and to Takeda (topic: gastroparesis). A.A.M.M. received funding from Pentax Europe GmbH. A.A.M.M. has received funding from the Dutch Cancer Society related to endoscopy and to colorectal polyps. A.B. reported no conflicts of interest.

Open Access This article is licensed under a Creative Commons Attribution 4.0 International License, which permits use, sharing, adaptation, distribution and reproduction in any medium or format, as long as you give appropriate credit to the original author(s) and the source, provide a link to the Creative Commons licence, and indicate if changes were made. The images or other third party material in this article are included in the article's Creative Commons licence, unless indicated otherwise in a credit line to the material. If material is not included in the article's Creative Commons licence and your intended use is not permitted by statutory regulation or exceeds the permitted use, you will need to obtain permission directly from the copyright holder. To view a copy of this licence, visit http://creativecommons.org/licenses/by/4.0/.

\section{References}

1. Besnard P, Passilly-Degrace P, Khan NA (2016) Taste of fat: a sixth taste modality? Physiol Rev 96(1):151-176. https://doi. org/10.1152/physrev.00002.2015

2. Lim J, Pullicin AJ (2019) Oral carbohydrate sensing: beyond sweet taste. Physiol Behav 202:14-25. https://doi.org/10.1016/j. physbeh.2019.01.021

3. Ij I, Renken RJ, Ter Horst GJ, Reyners AK (2015) Metallic taste in cancer patients treated with chemotherapy. Cancer Treat Rev 41(2):179-186. https://doi.org/10.1016/j.ctrv.2014.11.006

4. Roper SD (2014) TRPs in taste and chemesthesis. Handb Exp Pharmacol 223:827-871. https://doi.org/10.1007/978-3-31905161-1 5

5. Varghese S, Kubatka P, Rodrigo L, Gazdikova K, Caprnda M, Fedotova J, Zulli A, Kruzliak P, Busselberg D (2017) Chili pepper as a body weight-loss food. Int J Food Sci Nutr 68(4):392-401. https://doi.org/10.1080/09637486.2016.1258044

6. van Avesaat M, Troost FJ, Westerterp-Plantenga MS, Helyes Z, Le Roux CW, Dekker J, Masclee AA, Keszthelyi D (2016) Capsaicin-induced satiety is associated with gastrointestinal distress but not with the release of satiety hormones. Am J Clin Nutr 103(2):305-313. https://doi.org/10.3945/ajcn.115.123414

7. Depoortere I (2014) Taste receptors of the gut: emerging roles in health and disease. Gut 63(1):179-190. https://doi.org/10.1136/ gutjnl-2013-305112

8. Breslin PA, Spector AC (2008) Mammalian taste perception. Curr Biol 18(4):R148-155. https://doi.org/10.1016/j.cub.2007.12.017

9. Cines BM, Rozin P (1982) Some aspects of the liking for hot coffee and coffee flavor. Appetite 3(1):23-34. https://doi.org/10.1016/ s0195-6663(82)80034-2

10. Chambers L, Mobini S, Yeomans MR (2007) Caffeine deprivation state modulates expression of acquired liking for caffeine-paired flavours. Q J Exp Psychol (Hove) 60(10):1356-1366. https://doi. org/10.1080/17470210601154545

11. Dotson CD, Geraedts MC, Munger SD (2013) Peptide regulators of peripheral taste function. Semin Cell Dev Biol 24(3):232-239. https://doi.org/10.1016/j.semcdb.2013.01.004

12. Geraedts MC, Munger SD (2013) Gustatory stimuli representing different perceptual qualities elicit distinct patterns of neuropeptide secretion from taste buds. J Neurosci 33(17):7559-7564. https ://doi.org/10.1523/JNEUROSCI.0372-13.2013

13. Lieverse RJ, Jansen JB, van de Zwan A, Samson L, Masclee AA, Lamers CB (1993) Effects of a physiological dose of cholecystokinin on food intake and postprandial satiation in man. Regul Pept 43(1-2):83-89. https://doi.org/10.1016/0167-0115(93)90410-a

14. Lieverse RJ, Jansen JB, Masclee AA, Lamers CB (1995) Satiety effects of a physiological dose of cholecystokinin in humans. Gut 36(2):176-179. https://doi.org/10.1136/gut.36.2.176

15. Verdich C, Flint A, Gutzwiller JP, Naslund E, Beglinger C, Hellstrom PM, Long SJ, Morgan LM, Holst JJ, Astrup A (2001) A meta-analysis of the effect of glucagon-like peptide-1 (7-36) amide on ad libitum energy intake in humans. J Clin Endocrinol Metab 86(9):4382-4389. https://doi.org/10.1210/jcem.86.9.7877

16. Gutzwiller JP, Goke B, Drewe J, Hildebrand P, Ketterer S, Handschin D, Winterhalder R, Conen D, Beglinger C (1999) Glucagonlike peptide-1: a potent regulator of food intake in humans. Gut 44(1):81-86. https://doi.org/10.1136/gut.44.1.81

17. Batterham RL, Cowley MA, Small CJ, Herzog H, Cohen MA, Dakin CL, Wren AM, Brynes AE, Low MJ, Ghatei MA, Cone RD, Bloom SR (2002) Gut hormone PYY(3-36) physiologically inhibits food intake. Nature 418(6898):650-654. https://doi. org/10.1038/nature00887 
18. Gutzwiller JP, Drewe J, Ketterer S, Hildebrand P, Krautheim A, Beglinger C (2000) Interaction between CCK and a preload on reduction of food intake is mediated by CCK-A receptors in humans. Am J Physiol-Reg I 279(1):R189-R195

19. van der Wielen N, van Avesaat M, de Wit NJW, Vogels JTWE, Troost F, Masclee A, Koopmans SJ, van der Meulen J, Boekschoten MV, Muller M, Hendriks HFJ, Witkamp RF, Meijerink J (2014) Cross-species comparison of genes related to nutrient sensing mechanisms expressed along the intestine. PLoS ONE 9(9):ARTN e107531. https://doi.org/10.1371/journal.pone.01075 31

20. Young RL, Sutherland K, Pezos N, Brierley SM, Horowitz M, Rayner CK, Blackshaw LA (2009) Expression of taste molecules in the upper gastrointestinal tract in humans with and without type 2 diabetes. Gut 58(3):337-346. https://doi.org/10.1136/ gut.2008.148932

21. Bezencon C, le Coutre J, Damak S (2007) Taste-signaling proteins are coexpressed in solitary intestinal epithelial cells. Chem Senses 32(1):41-49. https://doi.org/10.1093/chemse/bj1034

22. Gu F, Liu X, Liang J, Chen JY, Chen FX, Li F (2015) Bitter taste receptor mTas2r105 is expressed in small intestinal villus and crypts. Biochem Bioph Res Co 463(4):934-941. https://doi. org/10.1016/j.bbrc.2015.06.038

23. Sternini C, Anselmi L, Rozengurt E (2008) Enteroendocrine cells: a site of "taste" in gastrointestinal chemosensing. Curr Opin Endocrinol Diabetes Obes 15(1):73-78. https://doi.org/10.1097/ MED.0b013e3282f43a73

24. Jang HJ, Kokrashvili Z, Theodorakis MJ, Carlson OD, Kim BJ, Zhou J, Kim HH, Xu X, Chan SL, Juhaszova M, Bernier M, Mosinger B, Margolskee RF, Egan JM (2007) Gut-expressed gustducin and taste receptors regulate secretion of glucagon-like peptide-1. Proc Natl Acad Sci USA 104(38):15069-15074. https ://doi.org/10.1073/pnas.0706890104

25. Rozengurt N, Wu SV, Chen MC, Huang C, Sternini C, Rozengurt E (2006) Colocalization of the alpha-subunit of gustducin with PYY and GLP-1 in L cells of human colon. Am J Physiol Gastrointest Liver Physiol 291(5):G792-802. https://doi.org/10.1152/ ajpgi.00074.2006

26. WHO (2018) Obesity and Overweight. https://www.who.int/en/ news-room/fact-sheets/detail/obesity-and-overweight. Accessed 10 December 2019

27. Andreozzi P, Sarnelli G, Pesce M, Zito FP, D’Alessandro A, Verlezza V, Palumbo I, Turco F, Esposito K, Cuomo R (2015) The bitter taste receptor agonist quinine reduces calorie intake and increases the postprandial release of cholecystokinin in healthy subjects. J Neurogastroenterol Motil 21(4):511-519. https://doi. org/10.5056/jnm 15028

28. Avau B, Rotondo A, Thijs T, Andrews CN, Janssen P, Tack J, Depoortere I (2015) Targeting extra-oral bitter taste receptors modulates gastrointestinal motility with effects on satiation. Sci Rep 5:15985. https://doi.org/10.1038/srep15985

29. Bitarafan V, Fitzgerald PCE, Little TJ, Meyerhof W, Jones KL, Wu T, Horowitz M, Feinle-Bisset C (2020) Intragastric administration of the bitter tastant quinine lowers the glycemic response to a nutrient drink without slowing gastric emptying in healthy men. Am J Physiol Regul Integr Comp Physiol 318(2):R263-R273. https://doi.org/10.1152/ajpregu.00294.2019

30. Bitarafan V, Fitzgerald PCE, Little TJ, Meyerhof W, Wu TZ, Horowitz M, Feinle-Bisset C (2019) Effects of intraduodenal infusion of the bitter tastant, quinine, on antropyloroduodenal motility, plasma cholecystokinin, and energy intake in healthy men. $\mathrm{J}$ Neurogastroenterol Motil 25(3):413-422. https://doi.org/10.5056/ jnm19036

31. Deloose E, Corsetti M, Van Oudenhove L, Depoortere I, Tack J (2018) Intragastric infusion of the bitter tastant quinine suppresses hormone release and antral motility during the fasting state in healthy female volunteers. Neurogastroenterol Motil 30(1):ARTN e13171. https://doi.org/10.1111/nmo.13171

32. Deloose E, Janssen P, Corsetti M, Biesiekierski J, Masuy I, Rotondo A, Van Oudenhove L, Depoortere I, Tack J (2017) Intragastric infusion of denatonium benzoate attenuates interdigestive gastric motility and hunger scores in healthy female volunteers. Am J Clin Nutr 105(3):580-588. https://doi.org/10.3945/ ajen.116.138297

33. Iven J, Biesiekierski JR, Zhao DX, Deloose E, O'Daly OG, Depoortere I, Tack J, Van Oudenhove L (2019) Intragastric quinine administration decreases hedonic eating in healthy women through peptide-mediated gut-brain signaling mechanisms. Nutr Neurosci 22(12):850-862. https://doi.org/10.1080/10284 15x.2018.1457841

34. Klaassen T, Alleleyn AME, van Avesaat M, Troost FJ, Keszthelyi D, Masclee AAM (2019) Intraintestinal delivery of tastants using a naso-duodenal-ileal catheter does not influence food intake or satiety. Nutrients. https://doi.org/10.3390/nu11020472

35. Little TJ, Gupta N, Case RM, Thompson DG, McLaughlin JT (2009) Sweetness and bitterness taste of meals per se does not mediate gastric emptying in humans. Am J Physiol Regul Integr Comp Physiol 297(3):R632-639. https://doi.org/10.1152/ajpre gu.00090.2009

36. Ma J, Bellon M, Wishart JM, Young R, Blackshaw LA, Jones KL, Horowitz M, Rayner CK (2009) Effect of the artificial sweetener, sucralose, on gastric emptying and incretin hormone release in healthy subjects. Am J Physiol Gastrointest Liver Physiol 296(4):G735-739. https://doi.org/10.1152/ajpgi.90708.2008

37. Mennella I, Fogliano V, Ferracane R, Arlorio M, Pattarino F, Vitaglione P (2016) Microencapsulated bitter compounds (from Gentiana lutea) reduce daily energy intakes in humans. Br J Nutr. https://doi.org/10.1017/S0007114516003858

38. Meyer-Gerspach AC, Biesiekierski JR, Deloose E, Clevers E, Rotondo A, Rehfeld JF, Depoortere I, Van Oudenhove L, Tack J (2018) Effects of caloric and noncaloric sweeteners on antroduodenal motility, gastrointestinal hormone secretion and appetiterelated sensations in healthy subjects. Am J Clin Nutr 107(5):707716. https://doi.org/10.1093/ajen/nqy004

39. Peters HPF, Koppenol W, Schuring EAH, Gouka R, Mela DJ, Blom WAM (2016) The effect of two weeks ingestion of a bitter tastant mixture on energy intake in overweight females. Appetite 107:268-273. https://doi.org/10.1016/j.appet.2016.08.013

40. Rogers PJ, Pleming HC, Blundell JE (1990) Aspartame ingested without tasting inhibits hunger and food-intake. Physiol Behav 47(6):1239-1243. https://doi.org/10.1016/0031-9384(90)90377 $-\mathrm{G}$

41. Steinert RE, Frey F, Topfer A, Drewe J, Beglinger C (2011) Effects of carbohydrate sugars and artificial sweeteners on appetite and the secretion of gastrointestinal satiety peptides. Br J Nutr 105(9):1320-1328. https://doi.org/10.1017/S000711451000512X

42. van Avesaat M, Troost FJ, Ripken D, Peters J, Hendriks HF, Masclee AA (2015) Intraduodenal infusion of a combination of tastants decreases food intake in humans. Am J Clin Nutr 102(4):729-735. https://doi.org/10.3945/ajcn.115.113266

43. Wolnerhanssen BK, Cajacob L, Keller N, Doody A, Rehfeld JF, Drewe J, Peterli R, Beglinger C, Meyer-Gerspach AC (2016) Gut hormone secretion, gastric emptying, and glycemic responses to erythritol and xylitol in lean and obese subjects. Am J Physiol Endocrinol Metab 310(11):E1053-1061. https://doi.org/10.1152/ ajpendo.00037.2016

44. Black RM, Leiter LA, Anderson GH (1993) Consuming aspartame with and without taste: differential effects on appetite and food intake of young adult males. Physiol Behav 53(3):459-466. https://doi.org/10.1016/0031-9384(93)90139-7

45. Walker E, Lo K, Tham S, Pahl M, Lomiwes D, Cooney J, Wohlers M, Gopal P (2019) New Zealand bitter hops extract reduces 
hunger during a $24 \mathrm{~h}$ water only fast. Nutrients. https://doi. org/10.3390/nu11112754

46. Moher D, Liberati A, Tetzlaff J, Altman DG, Group P (2010) Preferred reporting items for systematic reviews and meta-analyses: the PRISMA statement. Int J Surg 8(5):336-341. https://doi. org/10.1016/j.ijsu.2010.02.007

47. Sterne JAC, Savovic J, Page MJ, Elbers RG, Blencowe NS, Boutron I, Cates CJ, Cheng HY, Corbett MS, Eldridge SM, Emberson JR, Hernan MA, Hopewell S, Hrobjartsson A, Junqueira DR, Juni P, Kirkham JJ, Lasserson T, Li T, McAleenan A, Reeves BC, Shepperd S, Shrier I, Stewart LA, Tilling K, White IR, Whiting PF, Higgins JPT (2019) RoB 2: a revised tool for assessing risk of bias in randomised trials. BMJ 366:14898. https ://doi.org/10.1136/bmj.14898

48. Viechtbauer W (2010) Conducting meta-analyses in R with the metafor Package. J Stat Softw 36(3):1-48. https://doi. org/10.18637/jss.v036.i03

49. Dagan-Wiener A, Di Pizio A, Nissim I, Bahia MS, Dubovski N, Margulis E, Niv MY (2019) BitterDB: taste ligands and receptors database in 2019. Nucleic Acids Res 47(D1):D1179-D1185. https ://doi.org/10.1093/nar/gky974

50. Horne J, Lawless HT, Speirs W, Sposato D (2002) Bitter taste of saccharin and acesulfame-K. Chem Senses 27(1):31-38. https:// doi.org/10.1093/chemse/27.1.31

51. Tan VWK, Wee MSM, Tomic O, Forde CG (2019) Temporal sweetness and side tastes profiles of 16 sweeteners using temporal check-all-that-apply (TCATA). Food Res Int 121:39-47. https:// doi.org/10.1016/j.foodres.2019.03.019

52. Tao R, Cho S (2020) Consumer-Based sensory characterization of steviol glycosides (Rebaudioside A, D, and M). Foods. https:// doi.org/10.3390/foods9081026

53. Meyerhof W, Batram C, Kuhn C, Brockhoff A, Chudoba E, Bufe B, Appendino G, Behrens M (2010) The molecular receptive ranges of human TAS2R bitter taste receptors. Chem Senses 35(2):157-170. https://doi.org/10.1093/chemse/bjp092

54. Jéquier E (1994) Carbohydrates as a source of energy. Am J Clin Nutr 59(3):682S-685S

55. Lindemann B (1996) Taste reception. Physiol Rev 76(3):719-766

56. Nelson G, Chandrashekar J, Hoon MA, Feng L, Zhao G, Ryba NJ, Zuker CS (2002) An amino-acid taste receptor. Nature 416(6877):199-202. https://doi.org/10.1038/nature726

57. Zhao GQ, Zhang Y, Hoon MA, Chandrashekar J, Erlenbach I, Ryba NJ, Zuker CS (2003) The receptors for mammalian sweet and umami taste. Cell 115(3):255-266. https://doi.org/10.1016/ s0092-8674(03)00844-4

58. Hosaka H, Kusano M, Zai H, Kawada A, Kuribayashi S, Shimoyama Y, Nagoshi A, Maeda M, Kawamura O, Mori M (2012) Monosodium glutamate stimulates secretion of glucagon-like peptide- 1 and reduces postprandial glucose after a lipid-containing meal. Aliment Pharmacol Ther 36(9):895-903. https://doi. org/10.1111/apt.12050

59. Luscombe-Marsh ND, Smeets AJ, Westerterp-Plantenga MS (2009) The addition of monosodium glutamate and inosine monophosphate-5 to high-protein meals: effects on satiety, and energy and macronutrient intakes. Br J Nutr 102(6):929-937. https ://doi.org/10.1017/S0007114509297212

60. Prescott J (2004) Effects of added glutamate on liking for novel food flavors. Appetite 42(2):143-150. https://doi.org/10.1016/j. appet.2003.08.013

61. Dermiki M, Prescott J, Sargent LJ, Willway J, Gosney MA, Methven L (2015) Novel flavours paired with glutamate condition increased intake in older adults in the absence of changes in liking. Appetite 90:108-113. https://doi.org/10.1016/j.appet 2015.03.002
62. Steiner JE, Glaser D, Hawilo ME, Berridge KC (2001) Comparative expression of hedonic impact: affective reactions to taste by human infants and other primates. Neurosci Biobehav Rev 25(1):53-74. https://doi.org/10.1016/s0149-7634(00)00051-8

63. Yeomans MR, Durlach PJ, Tinley EM (2005) Flavour liking and preference conditioned by caffeine in humans. Q J Exp Psychol B 58(1):47-58. https://doi.org/10.1080/02724990444000041

64. Higgins MJ, Hayes JE (2019) Regional variation of bitter taste and aftertaste in humans. Chem Senses 44(9):721-732. https:// doi.org/10.1093/chemse/bjz064

65. Rogers PJ, Hogenkamp PS, de Graaf C, Higgs S, Lluch A, Ness AR, Penfold C, Perry R, Putz P, Yeomans MR, Mela DJ (2016) Does low-energy sweetener consumption affect energy intake and body weight? A systematic review, including meta-analyses, of the evidence from human and animal studies. Int J Obes (Lond) 40(3):381-394. https://doi.org/10.1038/ijo.2015.177

66. FDA US (2019) CFR - Code of Federal Regulations Title 21. https ://www.accessdata.fda.gov/scripts/cdrh/cfdocs/cfCFR/CFRSe arch.cfm?fr=172.575. Accessed 18 Dec 2019

67. El-Tawil S, Al Musa T, Valli H, Lunn MP, Brassington R, ElTawil T, Weber M (2015) Quinine for muscle cramps. Cochrane Database Syst Rev 4:CD005044. https://doi.org/10.1002/14651 858.CD005044.pub3

68. Agency MaHpR (2017) Quinine: reminder of dose-dependent QTprolonging effects; updated medicine interactions. https://www. gov.uk/drug-safety-update/quinine-reminder-of-dose-dependentqt-prolonging-effects-updated-medicine-interactions. Accessed 27 May 2020

69. Deloose E, Verbeure W, Depoortere I, Tack J (2019) Motilin: from gastric motility stimulation to hunger signalling. Nat Rev Endocrinol 15(4):238-250. https://doi.org/10.1038/s41574-019-0155-0

70. Zwirska-Korczala K, Konturek SJ, Sodowski M, Wylezol M, Kuka D, Sowa P, Adamczyk-Sowa M, Kukla M, Berdowska A, Rehfeld JF, Bielanski W, Brzozowski T (2007) Basal and postprandial plasma levels of PYY, ghrelin, cholecystokinin, gastrin and insulin in women with moderate and morbid obesity and metabolic syndrome. J Physiol Pharmacol 58(Suppl 1):13-35

71. le Roux CW, Batterham RL, Aylwin SJ, Patterson M, Borg CM, Wynne KJ, Kent A, Vincent RP, Gardiner J, Ghatei MA, Bloom SR (2006) Attenuated peptide YY release in obese subjects is associated with reduced satiety. Endocrinology 147(1):3-8. https ://doi.org/10.1210/en.2005-0972

72. Adam TC, Westerterp-Plantenga MS (2005) Glucagon-like peptide- 1 release and satiety after a nutrient challenge in normalweight and obese subjects. Br J Nutr 93(6):845-851. https://doi. org/10.1079/bjn20041335

73. Carroll JF, Kaiser KA, Franks SF, Deere C, Caffrey JL (2007) Influence of BMI and gender on postprandial hormone responses. Obesity (Silver Spring) 15(12):2974-2983. https:// doi.org/10.1038/oby.2007.355

74. Verdich C, Toubro S, Buemann B, Lysgard Madsen J, Juul Holst J, Astrup A (2001) The role of postprandial releases of insulin and incretin hormones in meal-induced satiety-effect of obesity and weight reduction. Int J Obes Relat Metab Disord 25(8):12061214. https://doi.org/10.1038/sj.ijo.0801655

75. Sumithran P, Prendergast LA, Delbridge E, Purcell K, Shulkes A, Kriketos A, Proietto J (2011) Long-term persistence of hormonal adaptations to weight loss. N Engl J Med 365(17):1597-1604. https://doi.org/10.1056/NEJMoa1105816

76. Chearskul S, Delbridge E, Shulkes A, Proietto J, Kriketos A (2008) Effect of weight loss and ketosis on postprandial cholecystokinin and free fatty acid concentrations. Am J Clin Nutr 87(5):1238-1246. https://doi.org/10.1093/ajcn/87.5.1238 